\title{
El discurso sobre la COVID-19: un estudio en la prensa de Italia, España y Alemania
}

\section{The discourse on COVID-19: a study in the Italian, Spanish and German press}

\author{
Reguero Sanz, I., Martín Jiménez, V., Berdón Prieto, P. y Herrero Izquierdo, J. ${ }^{1}$ \\ Recibido: 9-09-2020 - Aceptado: 20-01-2021 \\ https://doi.org/10.26441/RC20.1-2021-A13
}

\begin{abstract}
RESUMEN: Esta investigación analiza los artículos de opinión referidos a la COVID-19 publicados en los principales periódicos de Italia, España y Alemania. Para ello se ha empleado una metodología de análisis de contenido inductivo-deductivo de corte cualitativo a través de dos fases complementarias. Una primera, mediante el examen pormenorizado de la muestra y una segunda en la que se ha seguido un método de análisis textual comparado mediante el uso del software Sketch Engine. Los resultados muestran que existen unos temas comunes sobre el virus, aunque con enfoques diferentes según los países: una visión marcada por la política nacional en el caso español, más interpretativa en el caso alemán y más social-humanística en el italiano. Así, en los tres países estudiados un discurso contrario a generar pánico, pero con una clara subestimación del virus en sus primeros meses de aparición en el caso de la prensa de España e Italia.
\end{abstract}

Palabras clave: COVID-19; prensa; opinión; España; Italia; Alemania.

ABSTRACT: This research analyses the opinion articles about the COVID-19 published in the main newspapers of Italy, Spain and Germany. To this purpose, a qualitative inductive-deductive content analysis methodology has been used along two complementary phases. The first included the detailed analysis of the sample, and the second involved a method of comparative textual analysis using the Sketch Engine software. The results show the existence of some common issues about the virus, although with different approaches depending on the country: a certain vision marked by national politics in the Spanish case, an interpretative view in the case of Germany and a more social-humanistic perspective in the Italian dailies. A discourse contrary to generating panic is common in the three countries studied, but with a clear underestimation of the virus' potential consequences in the first couple of months after the outbreak in Wuhan as regards the Spanish and Italian press.

Keywords: COVID-19; press; opinion; Spain; Italy; Germany.

\footnotetext{
${ }^{1}$ Itziar Reguero Sanz es Doctora con mención internacional (Reino Unido), Premio Extraordinario en el Máster en Investigación de la Comunicación como Agente Histórico Social, por la Universidad de Valladolid, y profesora del Área de Periodismo. Sus líneas de investigación se centran en las relaciones de poder que se establecen entre políticos y medios, así como su posterior influencia en la sociedad. itziar.reguero@uva.es, https://orcid.org/0000-0002-3274-1861

Virginia Martín Jiménez es Doctora con Doctorado Europeo y Premio Extraordinario de Doctorado por la Universidad de Valladolid, profesora Titular del Área de Periodismo y forma parte del Grupo de Investigación en Nuevas Tendencias en Comunicación. Ha participado en casi una decena de proyectos de investigación competitivos y actualmente es parte del equipo de "Politainment en el entorno de la posverdad: nuevas narrativas, clickbait y gamificación” (Ref. CSO2017-84472-R). virginia.martin@uva.es, https://orcid.org/0000-0002-7099-1060

Pablo Berdón Prieto es Máster en Investigación de la Comunicación como agente histórico-social, Graduado en Publicidad y Relaciones Públicas e investigador predoctoral de la Universidad de Valladolid. Sus líneas de investigación se centran en la relación histórica de los medios de comunicación con el poder político. pablo.berdon@uva. es, https://orcid.org/0000-0002-5279-4426

Jacobo Herrero Izquierdo es Graduado en Periodismo con Máster en Investigación de la Comunicación como Agente Histórico Social e investigador predoctoral en la Universidad de Valladolid. Sus líneas de investigación se centran en el estudio del uso político de los medios de comunicación en momentos críticos de la historia. jacobo. herrero@uva.es, https://orcid.org/0000-0001-5672-3505
} 


\section{Introducción: planteamiento de la investigación ${ }^{2}$}

El 31 de diciembre de 2019, la Organización Mundial de la Salud (OMS) fue informada de varios casos de neumonía de causa desconocida detectados en la ciudad de Wuhan, provincia de Hubei (China) (Organización Mundial de la Salud, 2020a). A finales del mes de enero de 2020, la OMS definió la situación como de emergencia de salud pública de interés internacional por el impacto y la difusión de la enfermedad bautizada como COVID-19 (Organización Mundial de la Salud, 2020b), cuya expansión llevó a que dicha organización declarase, el 11 de marzo, pandemia al brote del nuevo coronavirus SARS-CoV-2 (Organización Mundial de la Salud, 2020c).

El impacto internacional de esta enfermedad en la conocida como sociedad de la información y el peso que han tomado ante este fenómeno los medios de comunicación (Casero-Ripollés, 2020; Lázaro-Rodríguez y Herrera-Viedma, 2020), reforzando así su función social y democrática de informar y construir opinión (Kovach y Rosenstiel, 2007; Habermas, 2006), conduce a estudiar el discurso sobre la COVID-19 en la opinión de la prensa europea en los primeros meses de la aparición de este fenómeno.

En concreto, la presente investigación se centra en el período transcurrido desde que el 31 de diciembre de 2019 se alertó en China de las primeras patologías, hasta que el 13 de marzo la OMS declarase a Europa el epicentro de la pandemia. Dentro de este marco cronológico se analizan los artículos de opinión, referidos al nuevo coronavirus 2019-nCoV y a la enfermedad que provoca, publicados en los principales periódicos nacionales de los tres países con mayor número de personas infectadas a nivel europeo a fecha de cierre de la investigación (Johns Hopkins University, 2020): Italia, España y Alemania.

El criterio para seleccionar los medios objeto de análisis fue, por un lado, el que fuesen periódicos de información general con implementación nacional ${ }^{3}$, y por otro, que ocupasen los primeros puestos en cuanto al número de lectores según los datos oficiales de cada país: El País y El Mundo en el caso de España, Corriere della Sera y La Repubblica en Italia y, para el estudio de Alemania, Süddeutsche Zeitung y Frankfurter Allgemeine Zeitung.

\section{Estado de la cuestión}

A pesar de la reciente aparición de la COVID-19, su destacado impacto social, político, económico y mediático ha generado la puesta en marcha de investigaciones que han recibido una rápida acogida por parte de las revistas académicas y por la comunidad científica. Así lo demuestran los trabajos que se han centrado en estudios bibliométricos de la producción científica sobre el nuevo coronavirus (Alba-Ruiz, 2020; Chahrour, et al., 2020; Torres-Salinas, 2020).

En relación con el ámbito de la presente investigación, la prensa y las noticias sobre el fenómeno del SARS-CoV-2 han sido abordados desde diversos puntos de vista (Lázaro-Rodríguez y Herrera-Viedma, 2020; Núñez Gómez et al., 2020), mientras que otros papers han optado por analizar el efecto de la pandemia desde el punto de vista del consumo de los medios (Casero-Ripollés, 2020; López-Rico et al., 2020; Montaña Blasco et al., 2020), de la comunicación corporativa (Xifra, 2020), de la manera en la que se ha informado desde las voces oficiales (Costa-Sánchez y LópezGarcía, 2020) y se ha hecho especial hincapié en el fenómeno de las fake news (Checa y Olmos, 2020; Cifuentes Faura, 2020; García Marín, 2020; Gutiérrez Coba et al., 2020; López Borrull, 2020; Román San Miguel et al., 2020; Villa Gracia y Cerdán Martínez, 2020).

\footnotetext{
${ }^{2}$ Esta investigación es resultado del proyecto "Politainment en el entorno de la posverdad: nuevas narrativas, clickbait y gamificación” (Ref. CSO2017-84472-R), financiado por el Ministerio de Economía y Competitividad (Gobierno de España).

${ }^{3}$ En Alemania, el diario más leído es el Bild, pero se descartó de la muestra por su estilo excesivamente sensacionalista y su formato tabloide. Le siguen en número de lectores los dos diarios seleccionados.
} 
Las redes sociales han despertado también interés entre la comunidad científica que ha optado por estudiar los contenidos sobre la COVID-19 difundidos en las diferentes plataformas digitales y el comportamiento de los usuarios (Thelwall y Thelwall, 2020; Thelwall y Levitt, 2020). Partiendo de estos avances, este artículo busca dar un paso más y acercarse al impacto mediático del coronavirus 2019-nCoV, pero desde la perspectiva de la opinión en la prensa y con una novedosa visión comparativa dentro del ámbito europeo.

\section{Objetivos y metodología}

La presente investigación tiene como objetivo principal analizar el discurso sobre la COVID-19 en la opinión de los dos medios escritos de información general más influyentes de cada uno de los siguientes países: Italia, España y Alemania. Con dicho análisis se busca trazar un estudio comparado entre los tres casos europeos a fin de comprobar si existen semejanzas o diferencias entre el tipo de discurso opinativo publicado por los rotativos y el enfoque (framing) empleado.

En esta línea se pueden diferenciar los siguientes objetivos específicos:

OI. Conocer cómo la prensa ha transmitido a la sociedad su opinión frente a la COVID-19 en sus primeros meses de existencia como tema noticioso.

OII. Analizar de forma empírica y comparada el discurso de la opinión sobre el nuevo coronavirus en los principales periódicos de los tres países examinados.

Para ello, se configuró una muestra a partir de todos los artículos de opinión publicados en las seis cabeceras seleccionadas -El País y El Mundo en el caso de España, Corriere della Sera y La Repubblica en Italia y, para el estudio de Alemania, Süddeutsche Zeitung y Frankfurter Allgemeine Zeitung-que hacían referencia (en cualquiera de sus acepciones o términos relacionados) a la COVID-19 y que se habían publicado, como se ha justificado anteriormente, del 31 de diciembre de 2019, en el que se conocen oficialmente los primeros casos en China, al 13 de marzo de 2020, fecha en la que Europa se convierte en el epicentro de la pandemia. Cabe mencionar que el trabajo empírico se extiende hasta el 15 de marzo para poder observar el impacto de lo sucedido dos días antes. Como puede verse en el Gráfico 1, la muestra se compone por un total de 338 artículos: 127 publicados en España, 126 en Italia y 85 en Alemania.

Gráfico 1. Número de piezas referentes a la COVID-19 por país

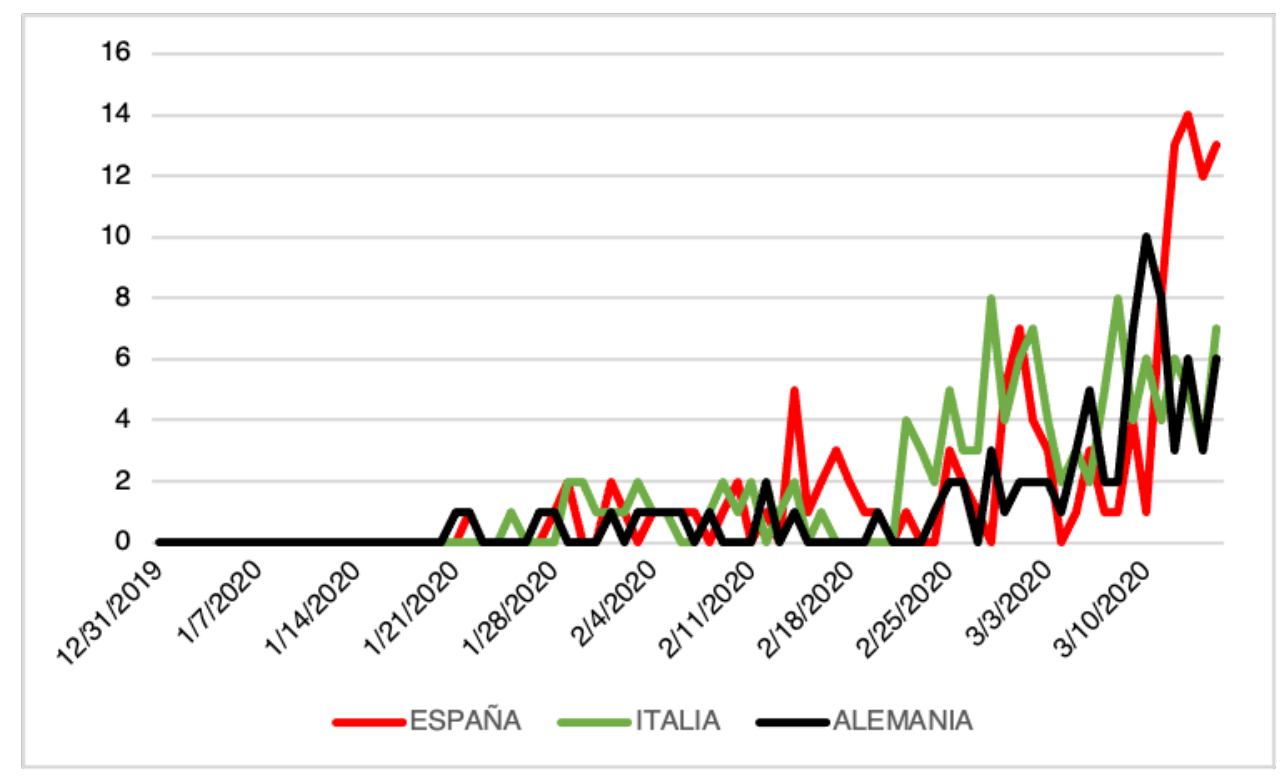

Fuente. Elaboración propia 
El método empleado se ha basado en un análisis de contenido inductivo-deductivo de corte cualitativo a través de dos fases complementarias. Una primera, mediante la observación, que permitió conocer el contenido de los artículos de opinión, el análisis pormenorizado de dichas piezas -en los dos meses y medio de estudio y en cada uno de los países- y el establecimiento de una serie de temas y lemas (palabras claves) frecuentes. Una vez analizado el contenido de dichos textos publicados por países, y habiéndose detectado una relación de temas que eran el leitmotiv de dichas piezas y cuya ocurrencia se mostraba en los tres Estados objeto de estudio, se pasó a una segunda fase de la investigación en la que se ha seguido un método de análisis textual mediante el uso del software Sketch Engine que ha permitido el proceso automático de la información, evitando sesgos lógicos del análisis de la opinión, ayudando al tratamiento y a la comparación multilingüe de las piezas estudiadas de cara a profundizar en el discurso de las cabeceras y en los marcos (frames) empleados (Touri y Koteyko, 2014; Kutter y Kanter, 2012).

Esta investigación se apoya en la teoría del constructivismo social mediático, defendida por autores como Scheufele (1999) y Semetko y Valkenburg (2000), que afirman que los mass media son un agente de primer orden a la hora de configurar una realidad modelada ${ }^{4}$. Tal y como expone Pinilla, "el espejo mediático capta porciones de realidad, corta el tiempo y el espacio en una superficie finita $[\ldots]$ es el interfaz que conecta al individuo con la realidad que le rodea. Una ventana abierta al complejo paisaje de la realidad" (2008: 92).

En este estudio se analiza el enfoque de la COVID-19 en la prensa escrita, lo cual se puede relacionar de forma directa con el framing. Esta teoría evoca la imagen de un marco que centra la atención sobre elementos específicos y ofrece una interpretación particular de un asunto entre muchas perspectivas posibles (López, et al., 2018: 42). En los medios son tan importantes los asuntos que se publican, como los argumentos con los que se definen dichas realidades sociales (Sádaba, 2001: 154). El frame analysis presenta grandes ventajas a nivel teórico y práctico para explicar la función de los medios como herramientas de poder. Además, su oportunidad metodológica permite realizar "estudios comparativos" (López Rabadán y Vicente Mariño, 2008: 9), como es el caso.

Asimismo, cabe resaltar de forma notoria la utilización de programas de análisis de corpus para realizar investigaciones en el marco de las Ciencias Sociales, tal y como señalan Kutter y Kantner (2012). Existen antecedentes de estudios que han utilizado el Sketch Engine en relación con el contenido y el encuadre (framing) de los medios de comunicación, los cuales avalan el método de esta investigación. En este sentido se pueden destacar los que abordan cuestiones desde la óptica de la prensa escrita como el racismo (Alcaraz Mármol y Soto Almela, 2016), el cambio climático (Moernaut et al., 2000), o asuntos referentes a la sección de opinión de las cabeceras (Izquierdo Alegría y González Ruiz, 2013)5.

\section{Resultados}

\subsection{El caso italiano: La Repubblica y Corriere della Sera}

La Repubblica y Corriere della Sera, en sus primeros artículos de opinión relacionados con el coronavirus, expusieron la situación que se estaba viviendo en China y de forma muy destacada

\footnotetext{
${ }^{4}$ Una gran cantidad de estudios, desde los ya clásicos de Park (1922), Lippmann (1922) y Lasswell (1927) señalan la influencia de los medios en el conocimiento acerca del entorno.

${ }^{5}$ También se ha utilizado el Sketch Engine para examinar discursos de los partidos políticos (Breeze, 2018).
} 
la falta de solidaridad y el racismo al que se veían sometidos sus ciudadanos en Europa ( $L R^{6}$ : Lerner, 2020a; Niola, 2020a; Recalcati, 2020a. CS: Polito, 2020). Desde Corriere se apuntó, a finales de enero, que ante la ausencia de una vacuna solo se podía actuar a través del aislamiento social, pese a la dificultad de esto último, y mediante la confianza en la ciencia y la financiación en investigación en las universidades (Harari, 2020). La opinión de ambas cabeceras al inicio de la crisis sostenía que la "entonces lejana" epidemia sólo se superaría si la sociedad estaba unida (LR: Rampini, 2020a; Matino, 2020a. CO: Bucchi, 2020; Buccini, 2020a). Se trataba de un comentario apoyado en la percepción de un mundo global y multidireccional y la influencia directa de China en el resto de países.

También en esta fase, La Repubblica trató de restar importancia a la nueva enfermedad, argumentando que existía una gran psicosis social, lo cual era más urgente erradicar que la propia COVID-19 (Niola, 2020a; De Gregorio, 2020). Es más, se dejaba entrever que Italia padecería una crisis económica, pero a costa del turismo chino, no porque se pensase realmente que el país fuese a correr peligro. Puede percibirse que la intención de este diario era evitar la "excesiva alarma" social frente al coronavirus: en los medios de comunicación ni siquiera había espacio para el resto de noticias, como las relativas a los asuntos ecológicos, las muertes infantiles o los bajos ingresos (Romagnoli, 2020). No obstante, sí existieron voces que alertaron de que el virus podía acarrear graves consecuencias: “¿Qué pasaría si la epidemia fuera mucho más grave de lo que quieren que creamos?” (Fraioli, 2020).

De este modo, el periódico apostó por hacer frente a la enfermedad (Colaprico, 2020), pero sin dar pie al miedo exacerbado. Algunos de los comentarios al respecto fueron los siguientes: "La reacción de pánico termina amplificando el peligro en sí mismo fuera de toda proporción" (Recalcati, 2020b); "El peligro de propagar la infección genera una preocupación legítima, pero si no se maneja adecuadamente, se convierte en pánico inútil” (Santangelo, 2020).

Ciertas cuestiones como la posibilidad de "morir solos", se veían incluso más amenazantes que el propio virus, según algunos articulistas (Diamanti, 2020a). Además, ambos diarios señalaron que los mensajes de pánico sobre la enfermedad eran especialmente peligrosos en la era de las redes sociales por la viralidad de los mismos. $L R$ : "En la era de los influencers, la gripe es aún más aterradora" (Niola, 2020b). CO: "Hay perfiles de Facebook y grupos de Whatsapp que parecen haberse dado una misión: asustar y asustarse [...] desahogar los miedos no es la mejor manera de superarlos" (Galli della Loggia, 2020a). A este respecto, Polito, en Corriere, achacaba el miedo a la desconfianza ciudadana en las autoridades y la sensación de una cierta indefensión ante la difícil situación sobrevenida (2020).

En los últimos días de febrero, la opinión de La Repubblica aseguraba que la política se enfrentaba a una gran prueba: las consecuencias, no solo sanitarias sino también económicas, parecían insalvables: "La enfermedad pasará tarde o temprano, pero la COVID-19 dejará escombros económicos ilimitados" (Giannini, 2020a). El país mediterráneo comenzaba a estar al nivel de China (Folli, 2020) por lo que había que hacer frente a la nueva situación: "Italia y Europa ya estaban estancadas antes del choque del coronavirus y deben reaccionar sin demora: después de salvar vidas, hay que cuidar [...] el trabajo y los ingresos de todos" (Rampini, 2020b). El mes se cerraba con 1128 contagiados y 29 fallecidos, cifras que no harían sino aumentar durante fechas sucesivas.

A partir de este momento surgen nuevos interrogantes como consecuencia de la rápida extensión del virus en el territorio italiano: ¿qué medidas había que tomar? Fontana, en Corriere, consideraba ne-

\footnotetext{
${ }^{6}$ A fin de facilitar la lectura, en determinadas citas se han sustituido los nombres de los diarios por sus propias siglas. LR: La Repubblica; CS: Corriere della Sera.
} 
cesario abrir una nueva fase "seria y responsable" pero igualmente "decidida a no causar más daño al país del necesario (miedo, alarmismo)" (2020). En La Repubblica, por su parte, se planteaban si era necesario el confinamiento. En los primeros días del mes de marzo, este diario dejaba entrever que el coronavirus era similar a la gripe (Diaspro, 2020) y que, de algún modo, se estaban tomando medidas precipitadas, que llevaban implícitas acciones desmedidas:

No digo que siempre haya mala fe, y que un miembro del parlamento pueda tener miedo, pero aparecer con una máscara es devastador para la comunicación de confianza en las instituciones. Cerrar las fronteras de una región a otra en el mismo país es tan grave como una infección viral, porque el virus puede erradicarse, la falta de solidaridad marcará las relaciones para siempre. [...] Y mientras tanto, la nación está paralizada incluso antes de que sea necesario (Matino, 2020b).

Desde el 5 de marzo, la perspectiva cambió en la prensa italiana. Más de 148 muertos y de 3800 contagiados (cifras oficiales), entre los cuales se encontraban la ministra regional de salud de Emilia-Romagna, Raffaele Donini, y la ministra de territorios, Barbara Lori. En aquel momento los diarios comenzaron a pedir responsabilidad a los ciudadanos para hacer frente al virus. La opinión del Corriere della Sera señalaba la importancia de limitar los contagios con un comportamiento responsable (Galli della Loggia, 2020a). "El amor, después de todo, es el mejor sistema inmunológico que tenemos" (Nevo, 2020). En la misma línea, La Repubblica apeló al significado actual de democracia (Giannini, 2020b); hay que potenciar las responsabilidades individuales para fomentar el bien común (Scalfari, 2020; Diamanti, 2020b): “Ante una amenaza excepcional, se necesita una respuesta igualmente excepcional. [...] La derrota es un lujo que no podemos permitirnos" (Giannini, 2020c). El egoísmo sería el peor de los males posibles y, por el contrario, "la compasión, la solidaridad, el compartir y el respeto por la vida del otro serán palabras para la nueva globalización" (Matino, 2020c).

A su vez, La Repubblica instó a la opinión pública a dejar de banalizar las muertes de la gente mayor, ya que sus vidas no valían menos que las de otros estratos de edad: "Las noticias cada hora son cada vez más preocupantes y el único consuelo para los infectados es: ¡los viejos son los que más mueren!" (Aspesi, 2020). Los ancianos respondían a estas declaraciones "con más molestia que miedo", porque se sienten desafiados una vez más "por razones médicas, demográficas y económicas" (Bianchi, 2020). Así, sobre esta cuestión, se plantearon nuevas preguntas que no tardarían en encontrar respuestas reales: “¿Qué pasaría si fuera obligatorio elegir entre una persona mayor y una joven para recibir tratamiento?" (Aspesi, 2020).

El 8 de marzo, Giuseppe Conte extendió la cuarentena para cubrir toda la región de Lombardía y otras catorce provincias del norte. Dos días después se declaró el confinamiento en toda Italia, restringiéndose también todo tipo de viajes y reuniones públicas. Dada la situación, los dos diarios aseguraban que se necesitaba más que nunca a Europa para salir de esta crisis, en la que los ciudadanos habían pasado del miedo a la angustia, atravesando la incertidumbre (CO: Daveri, 2020; Giavazzi, 2020; Ferrera, 2020. $R E$ : Giugliano, 2020). Cabe destacar dos citas muy similares de ambas cabeceras. Corriere: "No es el momento para que la Unión Europea imponga restricciones. Es hora de apoyarnos de todas las formas posibles, y con esto para calmar los mercados comunicando que Italia no se abandona a sí misma". La Repubblica: "En Europa, hoy se necesita una acción fuerte y unificada, no un acuerdo solo para otorgar ayuda a Italia, esperando ver quién tocará mañana. [...] Te esperamos a prueba de los hechos" (Penati, 2020).

Para tratar de evitar el desastre, es necesario confiar en la investigación: "La ciencia es algo serio que cura y cura a las personas, sin usar consignas ideológicas, operando en silencio y de manera efectiva" (Martino, 2020). Esta tesis la exponía Corriere de forma transversal desde finales de febrero (Di Vico, 2020; Marro, 2020; Postiglione, 2020), y La Repubblica a mediados de marzo (Mario de Notaris, 2020): "El crecimiento del conocimiento incluso en la contingencia actual es la 
única forma de esperar soluciones radicales en la dirección del bienestar individual” Asimismo, esta última cabecera señalaba que al finalizar la epidemia el país debía poner el foco en otros sectores públicos como la educación, la cual se enfrentaba a nuevos retos y lo hacía de forma satisfactoria (Fortini, 2020): "La escuela está viva y es capaz de dar respuestas. Y esto ciertamente lleva al optimismo incluso en un momento tan difícil".

Por último, los diarios celebraron la alta responsabilidad mostrada por los italianos. Imarisio, en $\mathrm{Co}$ rriere della Sera señalaba que, aunque al comienzo se habían equivocado "entre todo tipo de cláusulas y paranoia", habían sabido retirarse a tiempo (2020). Por su parte, Marzano, en La Repubbli$c a$, exponía que había una parte de la sociedad que no solo estaba confinada de forma responsable, sino que ayudaba a las personas más desfavorecidas. Esto significa "seguir creyendo en la belleza de la humanidad y tener esperanza en la vida, incluso cuando se está rodeado por la oscuridad de una pandemia" (2020).

En definitiva, y pese a las evidentes secuelas que se asumían, tanto en lo sanitario como en lo económico [se habla incluso de un "cisne negro" en la presidencia de Trump" (Gaggi, 2020)], no todas ellas estaban enfocadas desde una perspectiva negativa. Cuando todo termine llegará el momento de "autoexaminarse" (Galli della Loggia, 2020b), pero lo que está claro es que más que nunca las consecuencias de nuestras acciones no solo afectan a nuestras vidas, sino también a las de desconocidos y extraños con los que hemos establecido "una conexión sin precedentes". Recalcati añade, a este respecto: "De esta manera somos verdaderamente sociales, somos completamente libres" (2020c). Después de todo, y aunque se parezca, el coronavirus no es el Apocalipsis (Lerner, 2020b).

\subsection{El caso español: El País y El Mundo}

En el primer mes de estudio se publicaron muy pocas piezas de opinión relacionadas con la COVID-19, sin embargo, el diario El País dedicó editoriales al mal estado actual de la sanidad en España (2020a). Los primeros títulos que sí que hablaron directamente de ello compararon las consecuencias económicas que podría conllevar esta enfermedad con las del SARS de 2003. Surge aquí el término "cisne negro", que se repetirá en varios textos de El País (Estefanía, 2020; Lapuente, 2020).

Según avanzaba la enfermedad en China se fueron conociendo episodios racistas contra este pueblo en diversos puntos de occidente. Tanto El País como El Mundo mantuvieron una línea beligerante contra estos sucesos (Tsai Tseng, 2020; Palmero, 2020). Mientras que las comunidades de inmigrantes chinos eran ampliamente respaldadas desde las opiniones, su patria era fuertemente criticada por las dos cabeceras españolas en la primera semana de febrero. Los focos de la impopularidad china apuntaban a su régimen político dictatorial por su opacidad interna y la centralidad de la propaganda oficial del gobierno de Xi Jinping (Marirrodriga, 2020; Bassets, 2020a; Redondo, 2020; Torreblanca, 2020). Además de la cuestión racista y política de China, surgieron otros artículos enfocados desde diversas perspectivas: la importancia de la Organización Mundial de la Salud ( $E l$ País, 2020b) o el peso de la ciencia (Galindo, 2020).

En la segunda semana de febrero se comunicó la suspensión definitiva del Mobile World Congress de Barcelona. El País defendió en los primeros días que esa decisión era injustificada: "El miedo ha demostrado ser más contagioso que el propio virus y ha alcanzado a Barcelona, donde no existen motivos de alarma" (El País, 2020c). El Mundo, pese a que también mantuvo que no había razones científicas para la cancelación del evento tecnológico, señaló que la política ejercida por Ada Colau en el Consistorio había podido afectar en la decisión de los organizadores: 
El deterioro de la imagen de Barcelona en estos años, fruto tanto de la gestión populista de Ada Colau -turismofobia, aumento de la criminalidad- como del estallido del proceso separatista -la fuga de miles de empresas, las barricadas ardiendo tras la sentencia-, no contribuyeron a buen seguro a tranquilizar a los organizadores, que reclaman estabilidad política y social para hacer negocios en un entorno favorable ( $E l$ Mundo, 2020a).

La postura de este periódico ganó enteros puesto que, días después, la cabecera del Grupo PRISA se sumó a esa tesis (Trueba, 2020; Gil Calvo, 2020a). En la última semana de febrero el virus avanzó de forma transcontinental y llegó con fuerza a Italia. Esta expansión tuvo su reflejo en el temor por una repercusión notable en la economía mundial y ambos diarios españoles alertaron desde sus piezas de opinión de que había que mantener cierta cautela con las medidas sanitarias para que el turismo no se viera afectado (Pardo, 2020).

Pese a que El Mundo y El País dieron una mayor importancia a la vertiente económica de la enfermedad, comenzaron a desconfiar del clima de calma sanitaria que se mantenía desde las autoridades, puesto que no dejaban de aumentar los casos y de cancelarse eventos internacionales (Bueno, 2020; El Mundo, 2020b). Estas sospechas aumentaron exponencialmente según pasaron los días y los dos periódicos comenzaron a aparcar los temores económicos que habían llenado sus líneas en los días previos para dedicar sus piezas de opinión a la responsabilidad individual con el objetivo de no colapsar los sistemas sanitarios (Moyano, 2020; Hernández, 2020).

La primera semana de marzo, el coronavirus aminoró su inercia informativa y los artículos de opinión y editoriales tomaron perspectivas más reflexivas. La celebración del Día de la Mujer, el 8 de marzo, restó capacidad mediática a la COVID-19 e, incluso, se entremezclaron estos dos grandes temas en las columnas de opinión: "En sólo dos meses la violencia machista ha asesinado ya a trece mujeres, cuyos cadáveres llaman menos la atención que el estornudo de una señora en Mallorca" (Grandes, 2020). El periódico El País dedicó varias piezas al papel del periodismo como altavoz sobredimensionante de las noticias sobre la enfermedad (González, 2020; Gil Calvo, 2020b). El Mundo, en cambio, alertó de la mala política que se practica en España y mandó todo su apoyo a la ciencia y la investigación:

Algunos científicos solventes trabajan a destajo por encontrar una vacuna, una solución, una alternativa, un alivio para una población que cada día derrapa un metro más en el pánico. En este momento (y en otros tantos) ellos son quienes merecen todas las facilidades para investigar. Todo el respeto. Todo el silencio necesario. Pero eso va en contra del negocio de algunos políticos y su envés, ese nido de sacamuelas o voceros cuya berrea ocupa varios canales de televisión en una sola jornada (Lucas, 2020).

A partir del 9 de marzo, la línea que habían mantenido El País y El Mundo comenzó a distanciarse con motivo del anuncio de un aumento de casos el día después de la celebración del 8M. El diario dirigido por Soledad Gallego-Díaz defendió que la responsabilidad para controlar al virus debe ser compartida: "que la situación empeoraría, y que puede hacerlo aún más, está dentro del cálculo de probabilidades. Pero que no escape al control es el esfuerzo que debe convocar a los poderes públicos y a los ciudadanos, cada cual desde sus competencias" ( $E l$ País, 2020d). Entre sus líneas también se dejaba claro que "la gestión de la crisis no puede interpretarse en clave partidista" (El País, 2020e). El Mundo desoyó la petición de su compañero y adoptó una postura claramente en contra a la actuación del Gobierno de Pedro Sánchez por su falta de anticipación y por "[...] exponer a decenas de miles de mujeres al contagio" (El Mundo, 2020c). Los columnistas de Unidad Editorial dejaron claro su posicionamiento al mostrarse también en contra del cierre del Parlamento (Jiménez Losantos, 2020a), de la "socialización de responsabilidades" que desde la izquierda se pretendía hacer de esta crisis (Ellakuría, 2020) o comparando el ejemplo francés en el que el ministro de Sanidad comparecía frente a la prensa de forma diaria (Gil, 2020). 
La crítica de El Mundo continuó aun después de que la OMS declarara oficialmente a la COVID-19 como una pandemia. Desde el editorial se pidió la discriminación de la coalición de gobierno y el advenimiento de un gran pacto entre el PSOE y el PP (El Mundo, 2020d). En esta misma línea, David Jiménez Torres defendió que se controlara más al Gobierno y se preguntó si los responsables del Ejecutivo eran lo suficientemente maduros como para controlar esta situación:

Es muy difícil gestionar una crisis de este tipo, pero por eso mismo la acción de los responsables públicos debe fiscalizarse más, no menos. En el momento en que todos debemos actuar como adultos en la sala, también es responsable preguntar si es que antes no había ninguno (2020).

En estas fechas, El País no dedicó tanto peso en sus artículos de opinión al ruedo político nacional. No obstante, sí que deja claro que los culpables del crecimiento del coronavirus en España no son los miembros del gobierno sino la corriente económica predominante: "Habrá que hacer balance de los destrozos provocados por la revolución neoliberal" (Ramoneda, 2020). A nivel editorial, el periódico señaló que la solución a la vertiente económica de esta crisis tenía que llegar desde Europa: "Ingentes recursos presupuestarios, a todos los niveles administrativos. Sin catastrofismo, sino al compás de lo que requiera la coyuntura" (El País, 2020f).

El Mundo fue el primer medio en pedir que se impusiera el estado de alarma para solucionar posibles luchas entre las distintas comunidades autónomas para controlar el virus (2020e). No le bastó al periódico con que el Ejecutivo escuchara su petición y anunciara la aplicación del artículo 116 de la Constitución puesto que volvió a invitar a otras fuerzas (PP, Ciudadanos y Vox) para que propusieran un pacto al PSOE con la condición de expulsar de estos acuerdos a su principal socio de gobierno (Jiménez Losantos, 2020b). El País, en contraposición a El Mundo, sí que apoyó las medidas anunciadas por Pedro Sánchez, considerándolas óptimas para la lucha contra el virus ( $E l$ País, 2020g). Aparte de la vertiente política, el diario de PRISA comenzó a plantear debates más amplios como la sostenibilidad de la globalización: "Ojalá sirva también para aprender a prevenir, gestionar y coordinar mejor crisis que afectan a todos, o sea, para reforzar un sistema de gobernanza global ahora insuficiente" (Manzano, 2020).

La declaración del estado de alarma el 14 de marzo (que sugirió El Mundo) no supuso ningún cambio en la línea editorial de ese periódico, el cual consideró al equipo de Pedro Sánchez como "bisoño y sin solidez" (El Mundo, 2020f). El resto de columnas de opinión siguieron esta misma línea. El País continuó demostrando estar muy alejado de las tesis que defiende el otro diario de estudio. En su editorial aplaudió la decisión de Pablo Casado e Inés Arrimadas de apoyar el decreto del estado de alarma y advirtió de que "las medidas que adopte el Gobierno bajo el estado de alarma no se pueden juzgar por su popularidad o su impopularidad, sino por su necesidad y por el rigor en su aplicación" (El País, 2020h). Por primera vez, El País criticó a las manifestaciones del 8 de calificándolas como "imprudencia grave" y prosiguió abriendo debates tan amplios como el del poder de los estados y el peso de la colectividad frente al individuo (Gascón, 2020).

El 15 de marzo, último día estudiado en esta investigación, El País continuó centrando el debate sobre el coronavirus en la parte más económica del problema (El País, 2020i). Otros textos relevantes de ese día hablaron de la vuelta a la época de los superestados, del nuevo cambio en el paradigma mundial y de la oportunidad de Pedro Sánchez para demostrar su liderazgo (Bassets, 2020b; Vicent, 2020). El Mundo fundamentó las críticas del primer día con el estado de alarma en vigor a la división interna de un "gobierno pensado para el eslogan, no para la gestión" ( $E l$ Mundo, 2020b) y, de nuevo, a la celebración de la manifestación del 8M: "Las mujeres seguimos siendo las grandes cuidadoras de la sociedad y hemos estado expuestas a un gran riesgo. Os lo digo sin acritud, se agradecería una disculpa. Nos la merecemos" (Michel, 2020). En síntesis, El País y El Mundo compartieron una buena parte de los diagnósticos y soluciones al problema del 
nuevo virus hasta su expansión nacional. Antes de la segunda semana de marzo, los dos diarios centraron sus mayores temores en las cuestiones económicas. Sin embargo, la celebración de las manifestaciones del $8 \mathrm{M}$ supuso una ruptura total de esta sincronía y la confrontación de la línea editorial de los dos diarios.

\subsection{El caso alemán: Frankfurter Allgemeine Zeitung y Süddeutsche Zeitung ${ }^{7}$}

Las referencias a la crisis del nuevo coronavirus en la prensa alemana, en los primeros artículos en relación con esta temática, datan de los últimos días de enero y principios de febrero, prueba de que las dimensiones de la epidemia en el territorio alemán tardaron un poco más en atisbarse o, al menos, en trasladarse la opinión pública.

A lo largo del período estudiado, si bien el enfoque o el tono fueron cuestiones cambiantes -que pudieron responder a las diversas percepciones, interpretaciones o la propia línea discursiva de cada periódico-, existe un elemento que se mantuvo firme de principio a fin, y que no es solo un reflejo de la cobertura periodística, sino de cómo las diferentes esferas políticas, sociales o económicas afrontaron este acontecimiento histórico en Alemania. Dicho elemento guarda relación con el alto grado de desconocimiento e incertidumbre existente sobre la enfermedad y se hace visible en el hecho de que atributos como "novedoso", "incierto" o "extraño", entre otros similares, acompañaron frecuentemente al popularizado acrónimo de la COVID-19.

Lo anterior, sumado a un evidente contexto de desinformación, no deja de ser una réplica de la realidad misma, del discurso político y del pulso social que, sobre todo en los primeros meses del año 2020, fluctuó entre la infravaloración del poder del virus y el comprensible alarmismo. Aquí un ejemplo: "Todavía hoy numerosos rumores e incertidumbres sobre el virus siguen sin disiparse. Y esta especie de paquete bomba continúa alimentándose del vacío de información" (Müller-Jung, 2020). La incertidumbre, especialmente incómoda para los medios de comunicación de masas, se tradujo en toda una retahíla de términos; a veces próximos a la retórica belicista que optó por definir al virus como un "enemigo" (Schmidt, 2020), y otras tantas puramente metafóricos, como muestra el ejemplo del artículo del editor del $F A Z$, Berthold Kholer, que anunció la llegada de una "supertormenta" de una fuerza y alcance impredecible (Kholer, 2020a).

Ciertamente, las preguntas sobre el coronavirus han sido diversas y han estado presentes en varios escenarios, pero muchas de ellas no han hallado respuesta. La búsqueda de una contestación para todos los interrogantes — “¿Cuánto dura el período de incubación? ¿Cuál es la tasa de mortalidad? ¿Cuáles son las rutas exactas de infección? ¿Cuándo lleguen temperaturas más altas, se frenará la propagación?" (Ulrich, 2020) — explica la comparativa con la gripe común u otros patógenos, puntos de referencia para sendas cabeceras a la hora de situar el nuevo virus por encima o por debajo de una escala de virulencia: "Las epidemias de los últimos años, es decir, las de sarampión, gripe aviar, gripe porcina y ahora la del coronavirus, son principalmente de origen vírico. Este no será el último brote de virus poco conocidos anteriormente" (Bartens, 2020); "El coronavirus no es una epidemia de gripe normal. Hay vacuna para la gripe, pero no para el coronavirus" (Sturm, 2020).

Pese a la naturaleza impredecible del SARS-CoV-2, que desde el punto de vista sociológico presentaba un riesgo excepcional, los diarios alemanes no incurrieron en un tratamiento excesivamente sensacionalista. De hecho, ya desde los primeros textos editados por los periódicos, las referencias a la tranquilidad y a la prudencia predominaron por encima de la promoción del miedo o el pánico.

\footnotetext{
${ }^{7}$ De ahora en adelante nos referiremos a estos diarios como FAZ, en el caso del Frankfurter Allgemeine Zeitung, y como $S Z$, para hacer mención al periódico Süddeutsche Zeitung
} 
Así se observa en diversos titulares: "Paciencia en lugar de pánico" (Zinkant, 2020); "Sin enloquecer" (Pennekamp, 2020).

Conviene matizar que dichas apelaciones a la calma convivieron con un considerable número de piezas que igualmente advirtieron de las consecuencias devastadoras de la epidemia. Los ecos de la anterior crisis financiera, el desasosiego por un posible colapso en los mercados, las malas previsiones por la saturación de los hospitales y los anuncios del advenimiento de un periodo de inestabilidad fueron argumentos que aparecieron en la prensa germana. El temor y la sensación de peligro estuvieron presentes en los primeros estadios de la epidemia y los titulares de la prensa vuelven a ser ilustrativos: "Una epidemia del miedo" (Hegg, 2020); "Cuando avanza el peligro" (Schloemann, 2020).

Atendiendo a un relato más puramente cronológico, ha de advertirse un considerable aumento de las piezas de opinión a partir del mes de marzo, momento en el que brote alcanza la categoría de amenaza mundial. Los artículos difundidos durante la fase previa, durante enero y febrero de 2020, miraron fundamentalmente a China, a la región de Wuhan, al epicentro de una catástrofe repentina y difícil de manejar, pero no exenta de responsabilidades políticas, tal y como manifestaron los diarios: "La epidemia pudo haberse contenido mucho antes si las autoridades de la región hubieran advertido a la gente. China colocó el poder político por encima del bienestar de sus ciudadanos" (Deuber, 2020).

No deja de ser interesante el binomio China-comunismo presente en varios de los comentarios estudiados y que más de una vez sumó el calificativo de "autárquico", lo cual sirvió para representar un país inmerso en un sistema autoritario y donde la restricción de las libertades no era, como podía ser en Italia, algo extraordinario. Tal es así, que, mientras que el gigante asiático, el Partido Comunista chino y el sistema basado en el "férreo control social y económico" (Ankenbrand, 2020) destaparon cierto recelo en estos medios escritos, las primeras medidas de aislamiento tomadas por el Gobierno de Giuseppe Conte fueron, como manifestó el texto de Stefan Ulrich en el SZ, un "ejemplo" de superación en tiempos de necesidad (Ulrich, 2020).

Por otro lado, los artículos que abordaron en exclusiva la realidad en Alemania en esta primera fase no vacilaron a la hora de anunciar la gravedad de la situación. "El Gobierno Federal", apuntaba un artículo publicado el día 6 de este mes, se enfrenta actualmente a una "crisis nacional y mundial", y para hacerla frente, añadía más adelante, son necesarios "mensajes claros que orienten a todos los ciudadanos" (Ludwig, 2020). Firmeza, organización y “cooperación”, pedía en su comentario para el FAZ, Florentine Fritzen, unos días antes (Fritzen, 2020).

Con la llegada del carnaval, a finales de febrero, los casos por la enfermedad empezaron a aumentar de forma exponencial. Fue a partir de entonces cuando las piezas de opinión empezaron a alertar más seriamente de la gravedad de la crisis, la cual preocupaba tanto en su vertiente económica, como política y sanitaria: "La situación ha empeorado en los últimos días. Las infecciones por coronavirus se están propagando por todo el mundo como un incendio forestal que no reduce su fuerza. Arde aquí, luego allá, de repente en todas partes, incluso en Alemania. Ya no se pueden ignorar los extraños acontecimientos en diferentes lugares del mundo." (Illinger, 2020).

Respecto a los efectos económicos derivados de la propagación del virus, el $F A Z$ y $S Z$ coincidieron en sus referencias a la anterior crisis financiera del año 2008, así como en sus alabanzas a la política de ahorro llevada a cabo desde entonces:

La buena noticia en medio del número preocupante de infecciones es que Alemania y el resto de Europa, a día de hoy, sí están adecuadamente equipadas para contrarrestar las consecuencias económicas de la epidemia con medidas específicas. Hay suficiente dinero y suficiente poder para evitar el desempleo masivo y las bancarrotas (Gammelin, 2020a). 
En cualquier caso, y como señalaría más adelante el editor económico del FAZ, Gerald Braunberger, entrada la segunda semana de marzo, la imposibilidad de predecir la repercusión de la COVID-19 en los precios, en el trabajo o en el tejido empresarial, obligaba a relegar a un segundo plano la cuestión económica y a priorizar la seguridad de los médicos, enfermeros y sanitarios (Braunberger, 2020). Su artículo bajo el título "Esta no es la hora de los economistas", sucedió a otro publicado por el $S Z$ la semana anterior, también en la misma línea: "La política sanitaria es más importante que la económica" (Brinkmann, 2020).

En cuanto al tema político, deben señalarse al menos tres asuntos fundamentales: oportunismo, Unión Europea y sistema federal. El oportunismo político se refiere a las maniobras o decisiones poco comprensibles e incluso carentes de ética que la prensa alemana criticó con dureza al considerar que intentaban sacar rédito de una situación dramática e inusitada. Ejemplos de ello es el artículo de Berthold Kholer para la sección "Fraktur", donde el autor cargó contra el presidente norteamericano, Donald Trump, por culpar a los europeos de expandir el virus al otro lado del Atlántico, lo que justificaba su discurso proteccionista:

Trump volvió a encontrar unos chivos expiatorios que tienen la culpa de todo. Según su terrorífica historia, los europeos (continentales) trajeron el virus a América al igual que los antiguos conquistadores trajeron la sífilis. ¿Y quiénes son los mejores, es decir, los peores europeos? ¡Pues nosotros, los alemanes! (Kholer, 2020b)

Muy similar, aunque más centrado en el debate sobre las ventajas y desventajas de un mundo globalizado (Fromm, 2020b; Frankenberger, 2020a), fue el artículo de Stefan Kornelius, que miró con peligrosidad a ese "caldo de cultivo" de nacionalismos y populismos creado recientemente en diversos países, cuyo grito de "soberanía" escondía un sentimiento de disgregación. Sentimiento que, pese a lo que pudiera pensarse, no servía para combatir una pandemia, según su afirmación (Kornelius, 2020).

Reflexiones como estas, junto a otras redactadas por los periodistas del Süddeutsche Zeitung, diario de tendencia centrista y socialdemócrata, y relacionadas con la cooperación y la validez de la Unión Europea, ofrecen la gran nota diferenciadora entre los rotativos examinados. En este punto es importante señalar que, sin ser en ningún caso el $F A Z$, tradicionalmente conservador y liberal, un periódico euroescéptico, lo cierto es que el "diario del sur de Alemania" clamó con mayor insistencia por una necesaria y casi obligada "solidaridad europea" (Gammelin, 2020b).

Solidaridad y compromiso fue también lo que solicitaron algunos articulistas de sendas cabeceras al referirse a los distintos Estados federados y a su relación con el gobierno central, el tercer gran tema mencionado. Se han encontrado varios ejemplos de artículos sobre el coronavirus en los que también se discutió sobre la pertinencia del sistema federal para atajar las consecuencias de la enfermedad (Müller, 2020; Esslinger, 2020a). Probablemente destaque por encima del resto el texto que recogió el $S Z$ en su ejemplar del 11 de marzo, y que trazó en uno de sus párrafos finales la siguiente conclusión: "el federalismo es un instrumento para aprovechar la inteligencia colectiva y la competencia de los locales, pero no es una carta blanca para que cada uno haga lo que le venga en gana" (Esslinger, 2020b). También el firmado por el responsable de la sección política del FAZ, Jasper Von Altenbockum:

En Alemania, los desastres y las catástrofes sirven para recordar que el Gobierno, generalmente, sólo tiene un papel de coordinación y conducción, pero los Estados federados y los municipios gozan de capacidad de decisión e independencia para hacer su trabajo [...] una de sus funciones es contrarrestar el pánico (Von Altenbockum, 2020).

A modo de cierre, ha de subrayarse la percepción y la impresión de las ambas publicaciones de estar asistiendo a un evento histórico, a un suceso de época. No faltaron las menciones a otros aconte- 
cimientos cruciales de la contemporaneidad y antiguas catástrofes ocurridas en el último siglo. Lo ocurrido en Chernóbil en el año de 1986 o el atentado de las torres gemelas del 11 de setiembre de 2001 son algunos ejemplos significativos (Veser, 2020; Frankenberger, 2020b).

\subsection{Análisis comparado: la opinión sobre la COVID-19 en la prensa europea}

Tal y como se detalla en la metodología, una vez analizados los artículos de opinión publicados por países, se detectaron una serie de temas que eran el leitmotiv de dichas piezas y cuya ocurrencia se manifestaba en todos los rotativos examinados. Seleccionados los temas, se estudiaron de manera comparada mediante el programa Sketch Engine; cuyos resultados pueden leerse a continuación.

\subsubsection{China: cuando el virus era sólo una noticia del exterior.}

La opinión de la prensa italiana, española y alemana se fue haciendo eco de los primeros casos detectados en China y de la expansión del virus por el gigante asiático. Todas las cabeceras coinciden en las duras críticas hacia el sistema dictatorial chino y la falta de derechos democráticos de ese país; exigiendo responsabilidades al gobierno de Xi Jinping por anteponer el interés político "por encima del bienestar de sus ciudadanos" (Deuber, 2020), como se aprecia en el Gráfico 2.

Gráfico 2. Modificadores del lema "China" en los periódicos alemanes y españoles

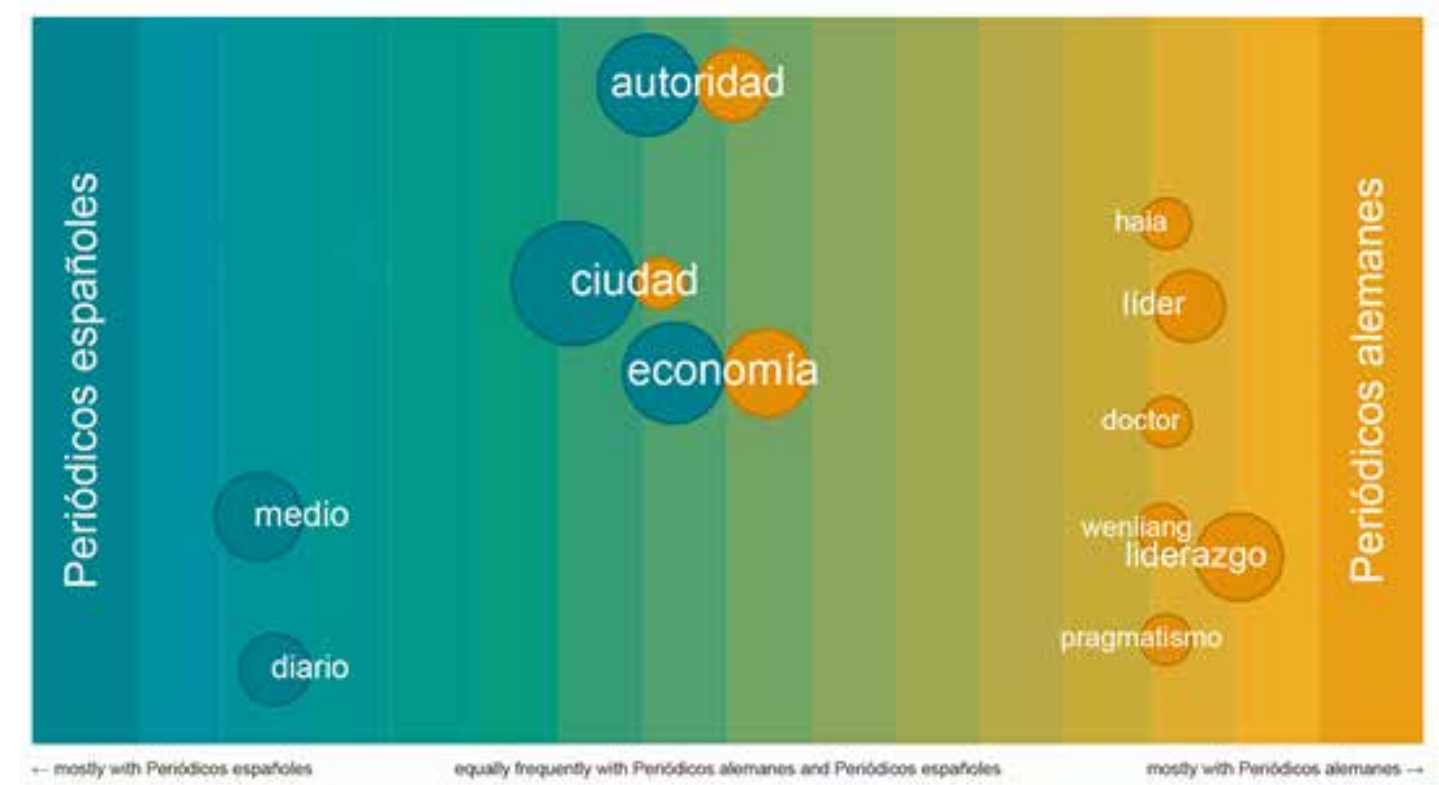

Fuente: Sketch Engine. Elaboración propia

El surgimiento de la enfermedad que sería bautizada como COVID-19 llevó a los articulistas europeos a atacar a una autoridad política opaca y propagandista que pocas garantías de veracidad y transparencia ofrecía internacionalmente sobre los datos e información que daba acerca de las propagación y consecuencias del virus (Marirrodriga, 2020; Bassets, 2020a; Redondo, 2020; Torreblanca, 2020). A la par que los artículos relacionaban el nuevo coronavirus con la autoridad china y su manera de gestionar la crisis; el término "economía" fue recurrente ya que se dará importancia a las consecuencias que iba a acarrear lo que estaba sucediendo en el terreno económico.

Los episodios racistas hacia la población china residente en Europa también protagonizaron, en el caso italiano y español, artículos de opinión que denunciaban lo que estaba sucediendo y clamaban 
por la solidaridad entre la ciudadanía al margen de su país de origen (LR: Lerner, 2020a; Niola, 2020a; Recalcati, 2020a. CS: Polito, 2020; Tsai Tseng, 2020; Palmero, 2020).

\subsubsection{COVID-19: ¿una gripe subestimada o el triunfo del alarmismo?}

En el período estudiado resulta recurrente la presencia en los artículos de opinión sobre el nuevo coronavirus de términos como "gripe" o "exageración" (o palabras relacionadas). Los diarios recuerdan el episodio de la conocida como gripe española de 1918; sin embargo, Alemania advierte de que se está subestimando el impacto de este brote de gripe vinculada a la COVID-19 mientras que los rotativos italianos lo adjetivan de "banal" o "normal" y los españoles lo califican de "común". Si bien en Italia, que emplea un discurso con más tendencia al dramatismo, encontramos términos como "letal", en España este no aparece y, cuándo no se banaliza de manera clara el virus, se le trata solo como una "fuerte" gripe.

La prensa alemana también se desmarca del caso italiano y español al mostrar una opinión más crítica y previsora hacia lo que podría estar por venir. Las firmas de los diarios estudiados advirtieron de las consecuencias devastadoras de la epidemia, recordaron los ecos de la anterior crisis financiera, mostraron su desasosiego por un posible colapso en los mercados o por las previsiones que hablaban de una rápida saturación de los hospitales (Hegg, 2020; Schloemann, 2020).

Por otra parte, a pesar de la preocupación que se observa en los medios germanos por la subestimación del virus, llama la atención que en todos los periódicos de los tres países estudiados se aprecia un sesgo de opinión común en los artículos (Gráfico 3); pues el término "exagerado", relacionado con la COVID-19 aparece cuando se habla de "cobertura", "respuesta", "reacción", "ansiedad" o "política".

Gráfico 3. Objetos que acompañan al lema "exagerado" en los periódicos alemanes y españoles

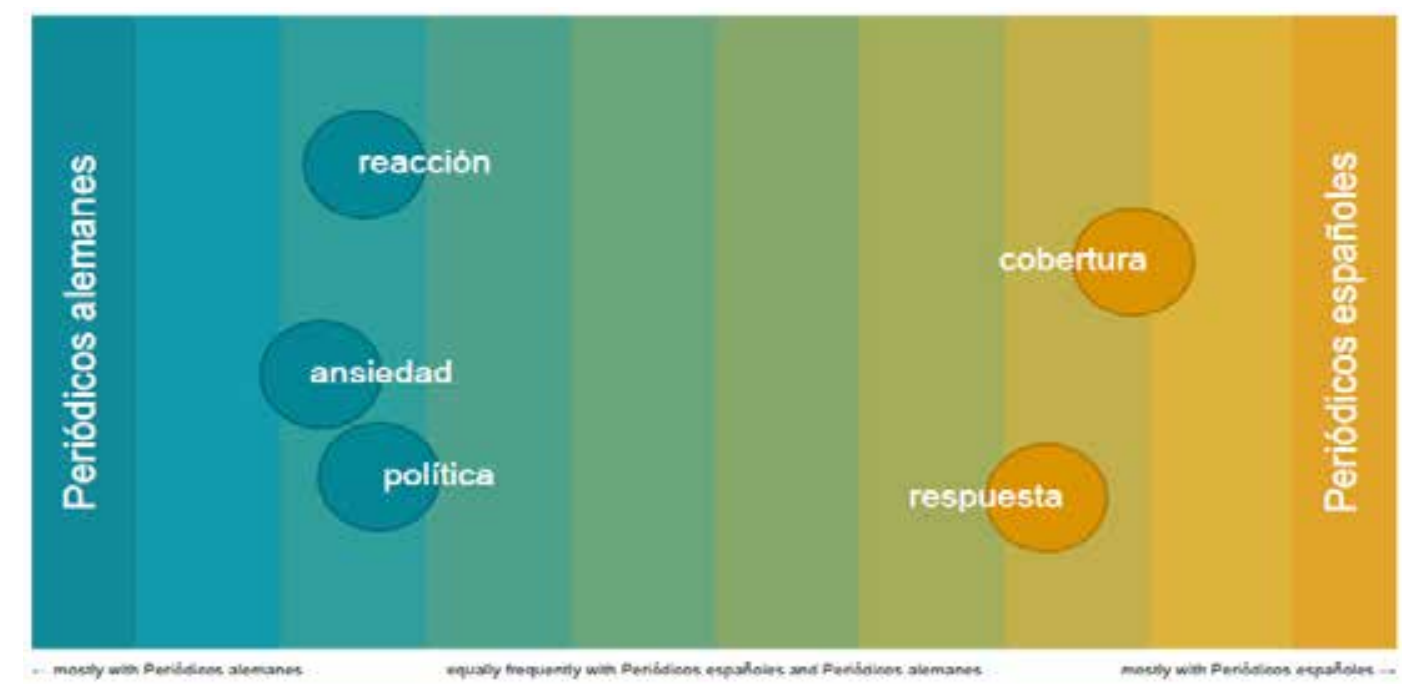

Fuente: Sketch Engine. Elaboración propia

El discurso sobre el miedo hacia la COVID-19, y las consecuencias catastróficas de que este afectara más que el propio virus, está presente en todos los medios estudiados, aunque con matices. En Italia y España se lanza un discurso frente a las primeras declaraciones de la OMS por temor a que ese pánico -entendido como algo sin fundamento-, afectase a la economía y el calificado como alarmismo tuviese peores consecuencias que las de la propia enfermedad (Colaprico, 23 febrero 
2020). A medida que el número de infectados se extiende por Italia, aumentan los artículos de opinión que llaman en España a la cautela con las medidas sanitarias para que el turismo no se viera afectado (Pardo, 2020). En esa misma línea se construye el discurso italiano preocupado también por la incidencia en el turismo de las medidas frente al virus.

Pero si nos fijamos en los términos empleados por la prensa alemana, se llama a la calma, pero como una apelación a la racionalidad de cara a afrontar la COVID-19 porque se entiende que el pánico desmedido es contraproducente (Zincant, 2020 o Pennekamp, 2020). Pero no porque se perciban, como sí lo hacen los rotativos italianos y españoles, "medidas precipitadas", "acciones desmedidas" o una "reacción de pánico" (Matino, 2020b) que acabe "amplificando el peligro en sí mismo fuera de toda proporción" (Recalcati, 2020b).

\subsubsection{Unión nacional frente al discurso politizado partidista}

En los artículos de opinión de la prensa italiana se hace referencia a la unidad nacional frente a la COVID-19 en el sentido de invocarla o ante el temor de perderla. En cambio, en la prensa española, como se señala en el Gráfico 4, encontramos el término unidad entendido como una exigencia frente a la amenaza del virus.

Gráfico 4. Objetos que acompañan al lema "unidad" en los periódicos italianos y españoles

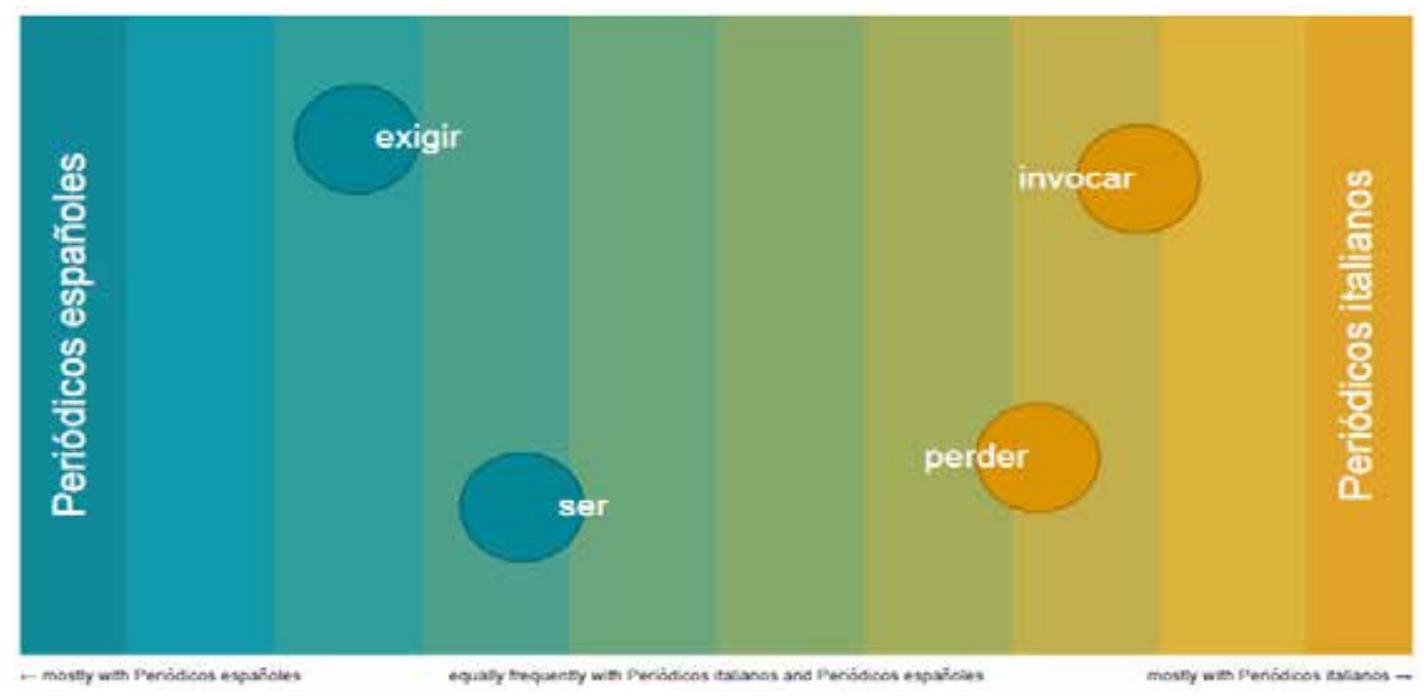

Fuente: Sketch Engine. Elaboración propia.

Entre España y Alemania, los resultados muestran que en los dos países se relaciona el nuevo coronavirus con "país" o "nación" unido a verbos negativos como "devastar" o "azotar"; sin embargo, en el caso alemán se vincula con la economía y la industria mientras que en España se hace con la propia realidad nacional que hay que "unir" y "reforzar".

La COVID-19 -y su impacto- lleva a la prensa europea a plantearse debates internos relacionados con el Gobierno y la estructura del Estado. Tanto en España como en Alemania, como se puede comprobar en el Gráfico 5, encontramos modificadores referentes a esta temática y en ambos casos se habla en estos artículos de la organización federal o autonómica del estado y su posible o no funcionalidad para enfrentarse a la enfermedad (Müller, 2020; Esslinger, 2020a); en el caso español, por su parte, se incluyen adjetivos negativos como "disfuncional" o "falto". Sin embargo, en relación al concepto "oposición parlamentaria" en Alemania no hay resultados mientras que los periódicos italianos lo incluyen en los artículos junto a la palabra "hablar" como una 
llamada al diálogo, mientras que en España se relaciona directamente con el propio "Gobierno": críticas hacia él (El Mundo, 2020a) o planteando que "la gestión de la crisis no puede interpretarse en clave partidista" (El País, 2020e) y que es necesario la "socialización de responsabilidades" (Ellakuría, 2020).

Gráfico 5. Modificadores que acompañan al lema "Gobierno" en los periódicos alemanes y españoles

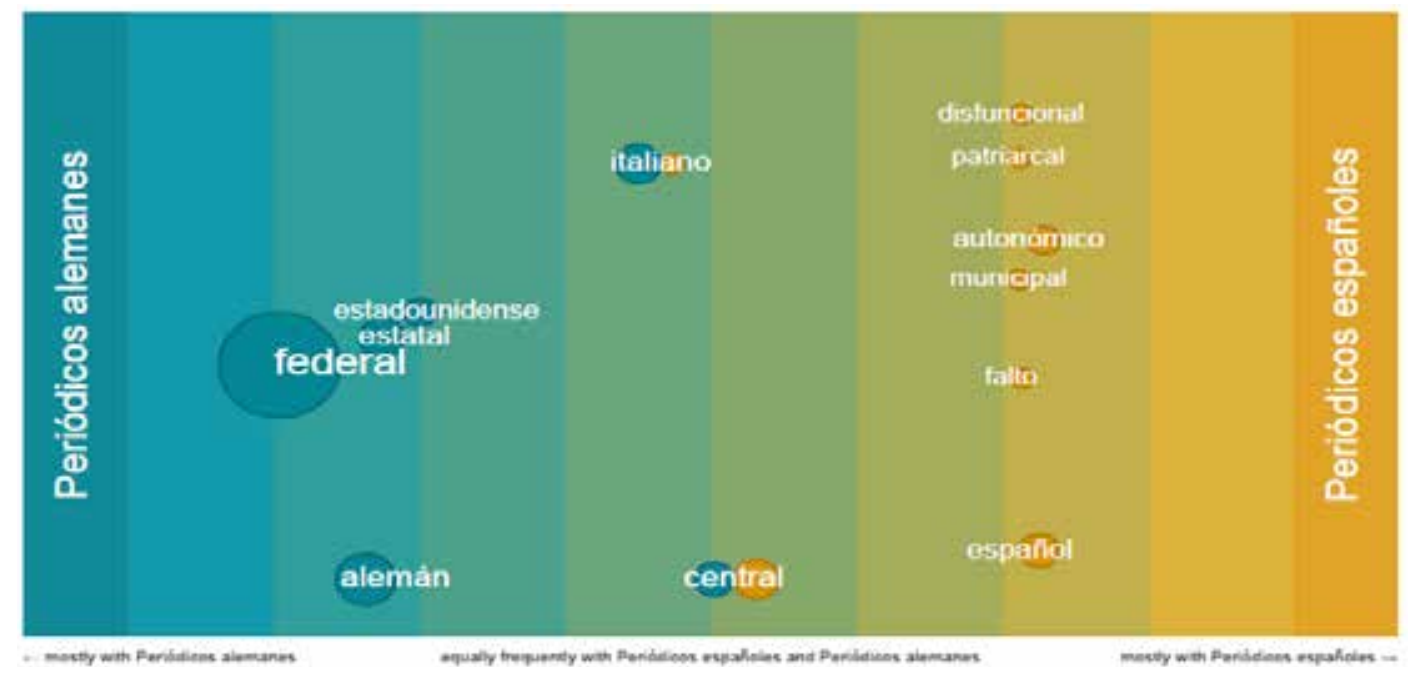

Fuente: Sketch Engine. Elaboración propia

\subsubsection{La Unión Europea ante la crisis del coronavirus SARS-CoV-2}

Un tema recurrente en los artículos de opinión sobre la COVID-19 es la Unión Europea y su papel ante la amenaza del coronavirus. Los resultados de la investigación muestran importantes diferencias entre el discurso de la prensa en España frente a la de Alemania: mientras que en los diarios de los primeros dos países se relaciona Europa y el nuevo virus con "asolar" o "exigir" en Alemania lo hacen con "necesitar" (Gráfico 6).

Gráfico 6. Verbos que acompañan al lema “europa” en los periódicos alemanes y españoles

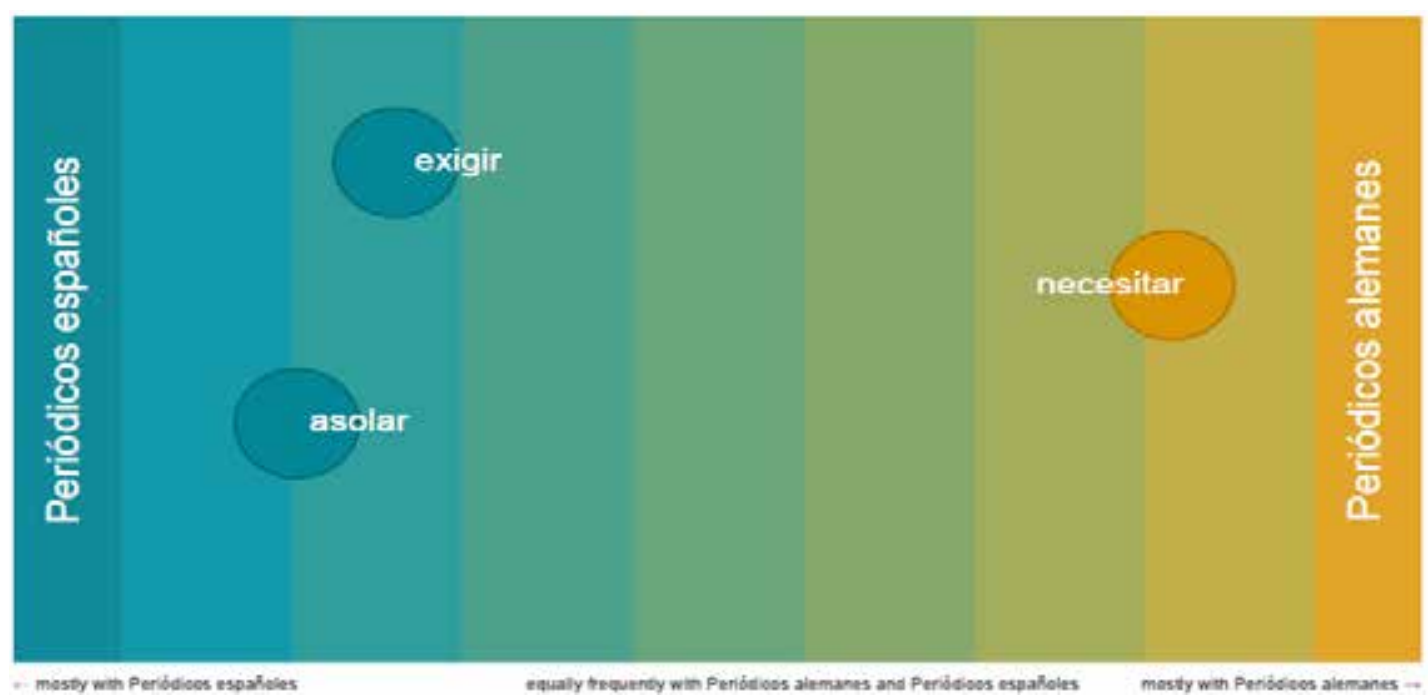

Fuente: Sketch Engine. Elaboración propia 
Esa postura de exigencia frente a Europa de los países del Mediterráneo se entiende en clave de que los diarios defienden que la solución a la vertiente económica de esta crisis tenía que llegar desde Europa y desarrollan un discurso utilitarista que pide una respuesta a la UE ( $E l$ País, 2020f). Frente a ello nos encontramos con el caso alemán donde la "solidaridad" (entendida como una necesaria obligación) tiene más peso en los artículos sobre el coronavirus planteados desde una perspectiva europea (Gammelin, 2020b). Cabe matizar que, si bien es coincidente el discurso hispano con el italiano, este último ofrece más puntos de vista sobre la UE y defienden de una manera más clara que la solución a la crisis viene de Europa (Penati, 2020).

\subsubsection{El confinamiento: ¿solución o medida desmedida?}

En los casos de Italia y España, el análisis de los textos muestra adjetivos que acompañan al término confinamiento (y sus variantes). Como se apunta en el Gráfico 7, en los medios españoles se encuentran un mayor número de referencias y, además, los modificadores exhiben más debate porque presentan términos contrapuestos "rígido"-“imprevisto" y con más potencia modificadora como "draconiano" o "inédito", mientras que en el caso de Alemania se califica a la cuarentena de "doméstica" o "preventiva".

Gráfico 7. Modificadores que acompañan al lema "cuarentena" en los periódicos alemanes y españoles

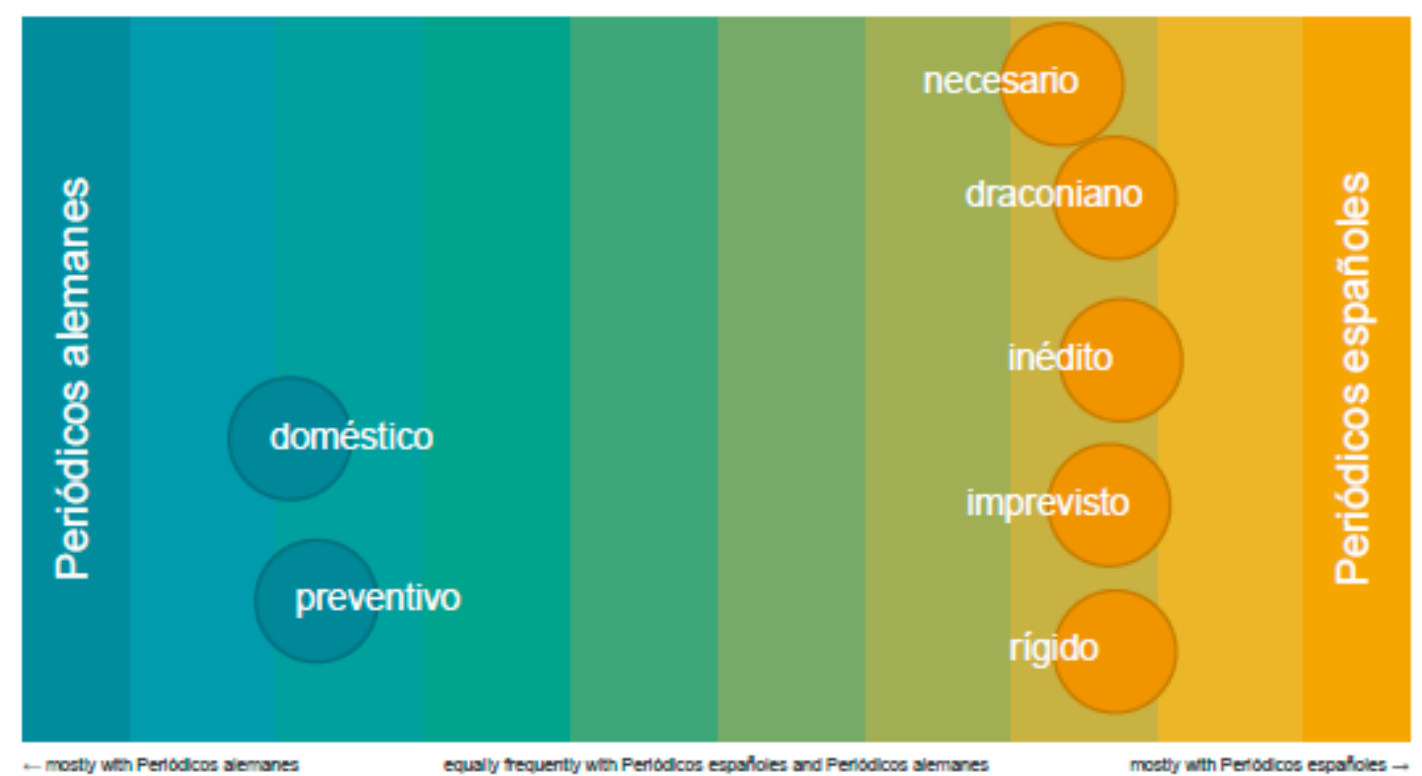

Fuente: Sketch Engine. Elaboración propia

Las alusiones al confinamiento o aislamiento en los periódicos alemanes estudiados se oponen a la visión negativa y reactiva presentes en el caso italiano y español. Así, cuando los artículos hablan de este tema, en Alemania lo hacen empleando verbos en sentido positivos ("creer" o "utilizar") mientras que en la prensa española se desarrolla el discurso en torno a la contraposición - "evitar" frente a "imponer" - y en Italia aparece de manera recurrente junto a "imponer" o "aceptar".

\section{Conclusiones}

Los resultados de la presente investigación han permitido conocer cómo la prensa europea -en el caso de Italia, España y Alemania- transmitió a la sociedad su opinión frente al nuevo coronavirus 
SARS-CoV-2 en sus primeros meses de existencia. Al mismo tiempo, ha ofrecido un análisis comparado del discurso sobre la COVID-19 publicado por las principales cabeceras de estos países, tanto a nivel cuantitativo como esencialmente cualitativo.

Una de las principales conclusiones que se extraen, relacionada con la forma en la que se desarrollaron las opiniones a lo largo del tiempo y con la teoría del enfoque o framing, permite hablar de distintas "fases en el interés hacia la COVID-19" por las que pasan todos los diarios, aunque en fechas diferentes. Habría así un primer periodo en el que China es protagonista en la prensa, la cual miró de forma crítica hacia el régimen político del gigante asiático, y unas etapas sucesivas que abarcan fundamentalmente los meses de febrero y marzo, donde las opiniones evolucionaron de acuerdo a la realidad nacional de cada territorio, si bien habría puntos coincidentes. En todos los países, por ejemplo, los diarios reconocieron los graves problemas económicos que iba a traer consigo la expansión del SARS-CoV-2, pero los casos italiano y español fueron más ilustrativos, posiblemente por la mayor fragilidad de estas economías.

El desembarco del coronavirus a más países a nivel mundial marca un claro punto de inflexión al reducir el debate sobre los posibles riesgos a nivel financiero y poner por delante la cuestión sanitaria. De nuevo habría que diferenciar entre los encuadres (frames) o esquemas de interpretación que realizan los periódicos de las distintas naciones. Aunque en este momento aún persistía el debate sobre si estaba predominando un pánico innecesario para manejar el virus, el crecimiento del número de infectados y fallecidos hizo que las opiniones girasen en torno a nuevos asuntos. La prensa italiana adoptó entonces un relato con un sentido social-humanístico que pidió la responsabilidad ciudadana para hacer frente a la crisis. Los diarios españoles, en cambio, se vieron envueltos en una lucha partidista a raíz de la manifestación del 8 de marzo, que llevó las opiniones al ruedo político. Alemania, por su parte, ofreció una visión más interpretativa sacando discusión debates como el futuro orden mundial que habría de imponerse después de la epidemia.

Las grandes diferencias, por tanto, llegaron en la forma en la que se trasladaron los temas principales a la opinión pública. Temas que, en líneas generales, sí fueron similares en todos los periódicos. Ya se ha señalado en las primeras líneas que la realidad china concentró la atención de la prensa en las fases iniciales, como luego lo haría la economía y más tarde la situación sanitaria. Habría casos más concretos como las comparativas del virus con la gripe, más prudente en la prensa alemana, las alusiones al papel de ayuda que debía desempeñar la Unión Europea, que para los diarios de España e Italia se entendía como una obligación, o las referencias al pánico y, al mismo tiempo, a mantener calma, que generaron visiones contradictorias.

Precisamente esa contradicción constituyó otro de los elementos comunes en buena parte de los diarios y que encuentra justificación en la dificultad de atisbar las consecuencias de una enfermedad desconocida. También coinciden las apelaciones a la unión y a la solidaridad para encarar la crisis y la reclamación de una acción decidida por parte de las instituciones políticas. En definitiva, cabría señalar que las opiniones de la prensa pivotaron sobre ciertos ejes (economía, salud, política y sociedad) que adquirieron mayor o menor peso en función de la actualidad noticiosa o incluso la ideología de las propias cabeceras, lo que igualmente sirvió para moldear los discursos. El análisis de los mismos ha permitido conocer la actuación de los periódicos en un momento inédito y en el que el rol de los medios se entendía determinante.

\section{Bibliografía}

Alba-Ruiz, R. (2020, 31 marzo). Covid-19, coronavirus pandemic: aproximación bibliométrica y revisión de los resultados. Zenodo. https://zenodo.org/record/3734062\#.X_1hvWRKiWY 
Alcaraz Mármol, G. y Soto Almela, J. (2016). The semantic prosody of the words inmigración and inmigrante in the Spanish written media: A corpus-based study of two national newspapers. Revista Signos. Estudios de lingüística, 49(91), 145 - 167. http://dx.doi.org/10.4067/S0718$\underline{09342016000200001}$

Ankenbrand, H. (2020, 12 de febrero). China im "Volkskrieg". Frankfurter Allgemeine Zeitung. https://www.faz.net/aktuell/gesellschaft/gesundheit/coronavirus/schaden-fuer-wirtschaft-china-imvolkskrieg-gegen-coronavirus-16628939.html

Aspesi, N. (2020, 8 marzo). Il coraggio della vecchiaia. La Repubblica. https://ricerca.repubblica. it/repubblica/archivio/repubblica/2020/03/08/il-coraggio-della-vecchiaia34.html?ref=search

Bartens, W. (2020, 20 de febrero). Die kommenden Seuchen. Süddeutsche Zeitung. https://www. sueddeutsche.de/gesundheit/coronavirus-impfung-kommentar-1.4806456

Bassets, L. (2020a, 16 de febrero). El virus autoritario. El País. https://elpais.com/ elpais/2020/02/15/opinion/1581783157 424338.html

Bassets, L. (2020b, 15 de marzo). Todos confinados. El País. https://elpais.com/elpais/2020/03/14/ opinion/1584208192_311717.html

Bianchi, E. (2020, 2 de marzo). Sommesso elogio della vecchiaia. La Repubblica. https://ricerca. repubblica.it/repubblica/archivio/repubblica/2020/03/02/sommesso-elogio-della-vecchiaia28. $\underline{\mathrm{html} \text { ?ref }=\text { search }}$

Braunberger, G. (2020, 13 de marzo). Das ist nicht die Stunde der Ökonomen. Frankfurter Allgemeine Zeitung. https://www.faz.net/aktuell/wirtschaft/mehr-wirtschaft/schwarzeboersenwoche-nicht-die-stunde-der-oekonomen-16676678.html

Breeze, R. (2011). Emotion in politics: Affective-discursive practices in UKIP and Labour. Discourse \& Society, (21), 93-116. https://www.redalyc.org/pdf/2870/287023883006.pdf

Brinkmann, B. (2020, 5 de marzo). Gesundheitspolitik ist jetzt wichtiger als Wirtschaftspolitik. Süddeutsche Zeitung. https://www.sueddeutsche.de/politik/corona-wirtschaft-folgen-konjunktur$\underline{\text { steuern-1.4830703 }}$

Bucchi, M. (2020, 10 de febrero). Il virus dall'Oriente e la malattia come metafora. Corriere della Sera. https://www.corriere.it/opinioni/20 febbraio_10/virus-straniero-67dbdf94-4c1f-11ea-91c6$\underline{061 \mathrm{fa} 519 \mathrm{fab} 0 . \mathrm{shtml}}$

Buccini, G. (2020, 13 de febrero). Più certezze e risposte serie. Il virus ci sta cambiando. Corriere della Sera. https://www.corriere.it/opinioni/20 febbraio_25/piu-certezze-risposte-serie-c43a4c22$\underline{\text { 57f4-11ea-a2d7-f1bec9902bd3.shtml }}$

Bueno, P. (2020, 26 de febrero). Fragilidades víricas. El País. https://elpais.com/ elpais/2020/02/25/opinion/1582638578 719871.html

Casero-Ripollés, A. (2020). Impact of Covid-19 on the media system. Communicative and democratic consequences of news consumption during the outbreak. El profesional de la información, 29(2). https://doi.org/10.3145/epi.2020.mar.23

Chahrour, M., Assi, S., Bejjani, M., Nasrallah, A. A., Salhab, H., Fares, M. Y. y Khachfe, H. H. (2020). A bibliometric analysis of Covid-19 research activity: A call for increased output. Cureus, 12(3) https://doi.org/10.7759/cureus.7357 
Checa y Olmos, F. (2020). Miedo y comunicación en tiempo de pandemia: de las fake news al humor. En C. Vázquez Domínguez, B. Pérez González y D. Salzano (Coord.), Cambio y coronavirus. Representaciones sociales: burla, silencio y miedo (pp. 29-44). McGraw Hill

Cifuentes Faura, J. (2020). Fake news during COVID-19: how to detect them? Comunicación, (42), 100-103.http://dx.doi.org/10.18566/comunica.n42.a07

Colaprico, P. (2020, 23 de febrero). Se Milano si scopre fragile. La Repubblica. https:// ricerca.repubblica.it/repubblica/archivio/repubblica/2020/02/23/se-milano-si-scopre-fragile34. $\underline{\mathrm{html} \text { ?ref }=\text { search }}$

Costa-Sánchez, C. y López-García, X. (2020). Comunicación y crisis del coronavirus en España. Primeras lecciones. El profesional de la información, 29(3). https://doi.org/10.3145/epi.2020.may.04

Daveri, F. (2020, 2 de marzo). La debolezza dell'Europa? Le divisioni tra i governi. Corriere della Sera. https://www.corriere.it/opinioni/20 marzo_02/debolezza-dell-europa-divisioni-governi04b39dbe-5cbc-11ea-9c1d-20936483b2e0.shtml

De Gregorio, C. (2020, 4 de febrero). La paura e l'ignoranza. La Repubblica. https://ricerca. repubblica.it/repubblica/archivio/repubblica/2020/02/04/la-paura-e-lignoranza28.html?ref=search

Deuber, L. (2020, 3 de febrero). Die Epidemie ist ein Versagen des autokratischen Systems. Süddeutsche Zeitung. https://www.sueddeutsche.de/politik/coronavirus-china-autokratie-1.478131

Di Vico, D. (2020, 28 de febrero). Le risorse di un Paese (nonostante la precarietà). Corriere della Sera. https://www.corriere.it/editoriali/20 febbraio_28/risorse-un-paesenonostante-precarietaff9f7be6-5a62-11ea-afa8-e7dfdde6e2a2.shtml

Diamanti, I. (2020a, 24 de febrero). Colpiti dal virus del l'insicurezza globale. La Repubblica. https:/ricerca.repubblica.it/repubblica/archivio/repubblica/2020/02/24/colpiti-dal-virus-dellinsicurezza-globale $32 . \mathrm{html}$ ?ref=search

Diamanti, I. (2020b, 9 de marzo). La paura della paura. La Repubblica, https://ricerca.repubblica. it/repubblica/archivio/repubblica/2020/03/09/la-paura-della-paura28.html?ref=search

Diaspro, A. (2020, 2 de marzo). Virus, l'esempio dell'ateneo. La Repubblica. https://ricerca. repubblica.it/repubblica/archivio/repubblica/2020/03/02/virus-lesempio-dellateneoGenova12. $\underline{\text { html? } \mathrm{ref}=\text { search }}$

El Mundo (2020a, 14 de febrero). Mobile: daño sin razón científica. El Mundo, https://www. elmundo.es/opinion/2020/02/14/5e45959cfdddffbe088b4742.html

El Mundo (2020b, 29 de febrero). Transparencia y pedagogía con el coronavirus. El Mundo. https://www.elmundo.es/opinion/editorial/2020/02/29/5e595e3cfdddff $21238 \mathrm{~b} 45 \mathrm{f} 3 . \mathrm{html}$

El Mundo (2020c, 11 de marzo). Por la unidad nacional contra la pandemia. El Mundo. https:// www.elmundo.es/opinion/2020/03/11/5e693fea21efa0332d8b45c9.html

El Mundo (2020d, 11 de marzo). Ya no es tiempo de poner parches. El Mundo. https://www. elmundo.es/opinion/2020/03/11/5e67fa7321efa0f16a8b460f.html

El Mundo (2020e, 13 de marzo). Una crisis en busca de líder. El Mundo. https://www.elmundo.es/ opinion/2020/03/13/5e6a8d3cfdddff 7 ba08b460b.html

El Mundo (2020f, 14 de marzo). Una gestión chapucera, improvisada y sin liderazgo. El Mundo. https:/www.elmundo.es/opinion/editorial/2020/03/13/5e6bea7ffc6c83432d8b46fc.html 
El Mundo (2020g, 15 de marzo). Una nación unida, un Ejecutivo roto e insolvente. El Mundo. https://www.elmundo.es/opinion/editorial/2020/03/15/5e6d46c021efa0252e8b4758.html

El País (2020a, 14 de enero). No es culpa de los pacientes. El País. https://elpais.com/ elpais/2020/01/13/opinion/1578943819_199358.html

El País (2020b, 1 de febrero). Confianza. El País. https://elpais.com/elpais/2020/01/31/ opinion/1580493145 691909.html

El País (2020c, 14 de febrero). Sin razones. El País. https://elpais.com/elpais/2020/02/13/ opinion/1581621470 349839.html

El País (2020d, 9 de marzo). Compromiso cívico. El País. https://elpais.com/elpais/2020/03/08/ opinion/1583685987_560251.html

El País (2020e, 11 de marzo). Decidir unidos. El País. https:/elpais.com/elpais/2020/03/10/ opinion/1583867279 206300.html

El País (2020f, 12 de marzo). A medio camino. El País. https://elpais.com/elpais/2020/03/11/ opinion/1583947875 081094.html

El País (2020g, 13 de marzo). Plan de alivio. El País. https://elpais.com/elpais/2020/03/12/ opinion/1584027878 888725.html

El País (2020h, 14 de marzo). Sumar o restar. El Pais. https:/elpais.com/elpais/2020/03/13/ opinion/1584121063 188693.html

El País (2020i, 15 de marzo). La hora del Estado. El País. https://elpais.com/elpais/2020/03/14/ opinion/1584213248_693482.html

Ellakuría, I. (2020, 11 de marzo). ¿Vida eterna? El Mundo. https://www.elmundo.es/ opinion/2020/03/10/5e67e65321efa06b2f8b45a4.html

Esslinger, D. (2020a, 13 de marzo). Solidarität wie nie. Süddeutsche Zeitung. https://www. sueddeutsche.de/meinung/coronavirus-deutschland-1.4843363

Esslinger, D. (2020b, 11 de marzo). Der Föderalismus kann eine Waffe sein. Süddeutsche Zeitung. https://www.sueddeutsche.de/politik/corona-foederalismus-1.4840253

Estefanía, J. (2020, 1 de marzo). Otro cisne negro. El País. https://elpais.com/elpais/2020/02/28/ ideas/1582908977_390566.html

Ferrera, M. (2020, 5 de marzo). L'emergenza è un'occasione per il buon uso dell'Europa. Corriere della Sera. https://www.corriere.it/editoriali/20 marzo 05/emergenza-un-occasioneperbuon-uso-dell-europa-7ba34f1c-5f16-11ea-bf24-0daffe9dc780.shtml

Folli, S. (2020, 26 de febrero). Il braccio di ferro dei perdenti. La Repubblica. https://ricerca.repubblica. it/repubblica/archivio/repubblica/2020/02/26/il-braccio-di-ferro-dei-perdenti28.html?ref=search

Fontana, L. (2020, 28 de febrero). Coronavirus, la normalità da riconquistare. Corriere della Sera. https://www.corriere.it/editoriali/20 febbraio_28/normalitada-riconquistare-f3b01652-599e-11eaaf71-899699a3d6d8.shtml

Fortini, L. (2020, 8 de marzo). Fare sistema, la nuova sfida della scuola campana. La Repubblica. https://ricerca.repubblica.it/repubblica/archivio/repubblica/2020/03/08/fare-sistema-la-nuovasfida-della-scuola-campanaNapoli29.html?ref=search 
Fraioli, L. (2020, 9 de febrero). Cosa c'è dietro la paura. La Repubblica. https://ricerca.repubblica. it/repubblica/archivio/repubblica/2020/02/09/cosa-ce-dietro-la-paura32.html?ref=search

Frankenberger, K. (2020b, 14 de febrero). Die Kehrseite gegenseitiger Abhängigkeiten. Frankfurter Allgemeine Zeitung. https:/www.faz.net/aktuell/politik/corona-pandemie-zeigtschattenseiten-der-globalisierung-16677934.html

Frankerberger, K. (2020a, 10 de marzo). Die Gründe für den Ölpreiskrieg. Frankfurter Allgemeine Zeitung. https://www.faz.net/aktuell/politik/ausland/russland-gegen-saudi-arabien-die-gruendefuer-den-oelpreiskrieg-16671394.html

Fritzen, F. (2020, 29 de febrero). Politik statt Panik. Frankfurter Allgemeine Zeitung. https://www. faz.net/aktuell/politik/inland/angst-vor-corona-politik-statt-panik-16657468.html

Fromm, T. (2020, 31 de enero). Das Coronavirus zwingt globalisierte Unternehmen zur Verantwortung. Süddeutsche Zeitung. https://www.sueddeutsche.de/wirtschaft/coronaviruswirtschaft-folgen-globalisierung-1.4777835

Gaggi, M. (2020, 12 de marzo). Il cigno nero di Donald Trump. Corriere della Sera. https:// www.corriere.it/opinioni/20 marzo 12/cigno-nero-af9f72c0-6482-11ea-90f7-c3419f46e6a5. shtml?refresh_ce

Galindo, J. (2020, 6 de febrero). Los buenos virus. El País. https://elpais.com/elpais/2020/02/05/ opinion/1580915755 626441.html

Galli della Loggia, E. (2020a, 7 de marzo). L'orgoglio di un Paese ammalato. Corriere della Sera. https://www.corriere.it/opinioni/20 marzo_07/orgoglio-un-paese-ammalato-8a09946e-60ae-11ea$\underline{8 \mathrm{~d} 61-438 \mathrm{e} 0 \mathrm{a} 276 \mathrm{fc} 4 . \mathrm{shtml}}$

Galli della Loggia, E. (2020b, 15 de marzo). Il passato ci frena ancora Scelte guidate dal consenso. Corriere della Sera. https://www.corriere.it/editoriali/20_marzo_15/passato-ci-frenaancorascelte-guidate-consenso-f9a05828-66fb-11ea-a26c-9a66211caeee.shtml

Gammelin, C. (2020a, 11 de marzo). Jetzt ist die Zeit für europäische Solidarität. Süddeutsche Zeitung. https://www.sueddeutsche.de/wirtschaft/coronavirus-wirtschaft-europa-hilfeitalien-1.4840553

Gammelin, C. (2020b, 13 de marzo). Die Regierung muss ihrem Versprechen nun Taten folgen lassen. Süddeutsche Zeitung. https://www.sueddeutsche.de/wirtschaft/coronavirus-krediteregierung-1.4843369

García-Marín, D. (2020). Infodemia global. Desórdenes informativos, narrativas fake y factchecking en la crisis de la Covid-19. El profesional de la información, 29(4). https://doi. org/10.3145/epi.2020.jul.11

Gascón, D. (2020, 14 de marzo). Apuntes sobre una epidemia. El País. https://elpais.com/ elpais/2020/03/13/opinion/1584103419_504912.html

Giannini, M. (2020a, 28 de febrero). Lo stress test di una nazione. La Repubblica. https:// ricerca.repubblica.it/repubblica/archivio/repubblica/2020/02/28/lo-stress-test-di-una-nazione32. $\underline{\mathrm{html} \text { ?ref }=\text { search }}$

Giannini, M. (2020b, 6 de marzo). L'antidoto al caos. La Repubblica. https://ricerca.repubblica.it/ repubblica/archivio/repubblica/2020/03/06/lantidoto-al-caos30.html?ref=search 
Giannini, M. (2020c, 10 de marzo). E adesso tocca a noi. La Repubblica. https://ricerca. repubblica.it/repubblica/archivio/repubblica/2020/03/10/e-adesso-tocca-a-noi28.html?ref=search

Giavazzi, F. (2020, 4 de marzo). La necessità di ripartire e l'esempio in Europa. Corriere della Sera. https://www.corriere.it/editoriali/20 marzo 04/10-cultura-aprecorriere-web-sezioni9e403c9e-5e5b-11ea-8e26-25d9a5210d01.shtml

Gil Calvo, E. (2020a, 18 de febrero). Cat.Exit. El Pais. https://elpais.com/elpais/2020/02/17/ opinion/1581944103 976316.html

Gil Calvo, E. (2020b, 3 de marzo). Dramatizar la agenda. El País. https://elpais.com/ elpais/2020/03/02/opinion/1583157669 735471.html

Gil, I. (2020, 10 de marzo). Virus, gobierno e ideología. El Mundo. https://www.elmundo.es/ opinion/2020/03/10/5e67e2f821efa07a758b4640.html

Giugliano, F. (2020, 15 de marzo). Bce, meglio tardi che mai. La Repubblica. https://ricerca.repubblica. it/repubblica/archivio/repubblica/2020/03/15/bce-meglio-tardi-che-mai36.html?ref=search

González, E. (2020, 1 de marzo). La muerte, modo de empleo. El País. https://elpais.com/ elpais/2020/02/27/ideas/1582827762_497106.html

Grandes, A. (2020, 2 de marzo). Prochina. El País. https://elpais.com/elpais/2020/02/29/ opinion/1582983069 955246.html

Gutiérrez-Coba, L., Coba-Gutiérrez, P. y Gómez-Díaz, J. (2020). Noticias falsas y desinformación sobre el Covid-19: análisis comparativo de seis países iberoamericanos. Revista Latina de Comunicación Social, (78), 237-264. https://www.doi.org/10.4185/RLCS-2020-1476

Habermas, J. (2006). Political communication in media society: Does democracy still enjoy an epistemic dimension? The impact of normative theory on empirical research. Communication theory, 16(4), 411-426. https://doi.org/10.1111/j.1468-2885.2006.00280.x

Harari, S. (2020, 14 de febrero). Ricerca, la lezione del virus. Corriere della Sera. https:// www.corriere.it/opinioni/20_febbraio_14/ricerca-lezione-cina-088a9dd8-4f52-11ea-9a70$\underline{00 \mathrm{e} 155903 \mathrm{~d} 81 . \mathrm{shtml}}$

Hegg, T. (2020, 13 de febrero) Eine Epidemie der Angst. Frankfurter Allgemeine Zeitung. https:// www.faz.net/aktuell/gesellschaft/gesundheit/coronavirus/mwc-kommentar-zur-absage-wegencorona-virus-16632668.html

Hernández, J. F. (2020, 29 de febrero). La tos del mundo. El País. https://elpais.com/ elpais/2020/02/29/opinion/1582933157_132876.html

Illinger, P. (2020, 29 de febrero). Krankeheit Angs. Süddeutsche Zeitung. https://www. sueddeutsche.de/gesundheit/corona-angst-covid-19-1.4824774

Imarisio, M. (2020, 10 de marzo). Il nuovo ponte di Genova «curerà» anche l'Italia ferita e isolata. Corriere della Sera. https://www.corriere.it/editoriali/20 marzo 10/10-culturadocumentofcorriere-web-sezioni-10d246b2-62fd-11ea-a693-c7191bf8b498.shtml

Izquierdo A., Dámaso y González Ruiz, R. (2013). La evaluación a través de un mecanismo cohesivo: las etiquetas discursivas en un corpus de editoriales. En C. Llamas Saiz, C. Martínez Pasamar y M. Casado Velarde. Léxico y argumentación en el discurso público actual (pp.149185). Peter Lang. 
Jiménez Losantos, F. (2020a, 10 de marzo). Cierran el Parlamento. El Mundo. https://www. elmundo.es/opinion/columnistas/2020/03/10/5e67eb54fc6c837c2f8b45cb.html

Jiménez Losantos, F. (2020b, 13 de marzo). 'Solutions Cum Fraude'. El Mundo. https://www. elmundo.es/opinion/columnistas/2020/03/12/5e6a7c3b21efa0e7658b4605.html

Jiménez Torres, D. (2020, 11 de marzo). Adultos en la sala. El Mundo. https://www.elmundo.es/ opinion/columnistas/2020/03/11/5e6930a2fdddffa2908b4574.html

Johns Hopkins University (2020, 15 de marzo). COVID-19 Dashboard by the Center for Systems Science and Engineering (CSSE). https://coronavirus.jhu.edu/map.html

Kholer, B. (2020a, 2 de marzo) Die Angst vor dem Supersturm. Frankfurter Allgemeine Zeitung. https://www.faz.net/aktuell/politik/inland/eine-wiederholung-von-merkels-grenzpolitik-istunvorstellbar-16660327.html

Kholer, B. (2020b, 13 de marzo). Ganz wie Mephisto. Frankfurter Allgemeine Zeitung. https:// www.faz.net/aktuell/politik/fraktur/ganz-wie-mephisto-16677876.html

Kornelius, S. (2020, 8 de marzo). Der große Rückzug. Süddeutsche Zeitung. https://www. sueddeutsche.de/politik/globalisierung-isolationismus-coronavirus-1.4834393

Kovach, B. y Rosenstiel, T. (2007). The elements of journalism: What newspeople should know and the public should expect. Three Rivers Press.

Kutter, A. y Kantner, C. (2012). Corpus-Based Content Analysis: A Method for Investigating News Coverage on War and Intervention. International Relations Online Working Paper, 1. http:// www.uni-stuttgart.de/soz/ib/forschung/IRWorkingPapers

Lapuente, V. (2020, 3 de marzo). Nuestro cisne negro. El País. https://elpais.com/ elpais/2020/03/02/opinion/1583151840_655363.html

Lasswell, H. D. (1927). The theory of political propaganda. American Political Science Review, 21, 627-631. https://doi.org/10.2307/1945515

Lázaro-Rodríguez, P. y Herrera-Viedma, E. (2020). Noticias sobre Covid-19 y 2019-nCoV en medios de comunicación de España: el papel de los medios digitales en tiempos de confinamiento. El profesional de la información, 29(3) https://doi.org/10.3145/epi.2020.may.02

Lerner, G. (2020a, 29 de enero). Cattiveria al potere. La Repubblica, https://ricerca.repubblica.it/ repubblica/archivio/repubblica/2020/01/29/cattiveria-al-potere26.html?ref=search

Lerner, G. (2020b, 12 de marzo). La normalità perduta. La Repubblica. https://ricerca.repubblica. it/repubblica/archivio/repubblica/2020/03/12/la-normalita-perduta30.html?ref=search

Lippmman, W. (1922). Public Opinion. Harcourt, Brace \& Co.

López Rabadán, P. y Vicente Mariño, M. (2008) Tendencias actuales en la investigación sobre framing: consolidación internacional y emergencia en la academia española. Investigar la Comunicación. Actas del Congreso Internacional Fundacional de la Asociación Española de Investigación en Comunicación. Santiago de Compostela.

López-Borrull, A. (2020). Fake news e infodemia científica durante la Covid-19, ¿dos caras de la misma crisis informacional? Anuario ThinkEPI, 14. https://doi.org/10.3145/ thinkepi.2020.e14e07 
López-Rico, C., González-Esteban, J. L. y Hernández-Martínez, A. (2020). Polarización y confianza en los medios españoles durante el Covid-19. Identificación de perfiles de audiencia. Revista Española de Comunicación en Salud, suplemento, 1, 77 - 89. https://doi.org/10.20318/recs.2020.5439

López, G., Gamir, J. y Valera, L. (2018). Comunicación política. Teorías y enfoques. Síntesis.

Lucas, A. (2020, 6 de marzo). Mascarillas. El Mundo. https://www.elmundo.es/ opinion/2020/03/06/5e615096fdddffcf5c8b468e.html

Ludwig, K. (2020, 6 de marzo). Die Politik hat die Virusangst unterschätzt. Süddeutsche Zeitung. https://www.sueddeutsche.de/politik/corona-virus-krise-hamsterkaeufe-1.4832408

Manzano, C. (2020, 13 de marzo). La gran disrupción. El País. https://elpais.com/ elpais/2020/03/12/opinion/1584019891_605008.html

Mario de Notaris, M. (2020, 10 de marzo). La cultura si fa senza"stare insieme. La Repubblica. https://ricerca.repubblica.it/repubblica/archivio/repubblica/2020/03/10/la-cultura-si-fa-senzastareinsiemeNapoli15.html?ref=search

Marirrodriga, J. (2020, 17 de febrero). El coronavirus no tiene ideología, quienes lo han ocultado, sí. El País. https:/elpais.com/elpais/2020/02/17/opinion/1581963132_699173.html

Marro, E. (2020, 1 de marzo). È necessario un cambio di passo. Corriere della Sera. https:// www.corriere.it/editoriali/20_marzo 01/necessario-cambio-passo-8663a544-5be9-11 ea-ae 74$\underline{\text { e93752023e91.shtml }}$

Martino, G. (2020, 5 de marzo). Ignoranza scientifica dilagante, il coronavirus stimoli la ricerca. Corriere della Sera. https://www.corriere.it/salute/20 marzo 05/coronavirus-stimoli-ricerca7cd511ea-5d5e-11ea-ad92-9d72350309c8.shtml

Marzano, M. (2020, 12 de marzo). Arcobaleni contro la paura. La Repubblica. https://ricerca. repubblica.it/repubblica/archivio/repubblica/2020/03/12/arcobaleni-contro-la-paura30.html?ref=search

Matino, G. (2020a, 9 de febrero). Ascoltiamo la città che soffre. La Repubblica, https://ricerca. repubblica.it/repubblica/archivio/repubblica/2020/02/09/ascoltiamo-la-citta-che-soffreNapoli21. $\underline{\mathrm{html} \text { ?ref }=\text { search }}$

Matino, G. (2020b, 1 de marzo). Coronavirus, chi soffia sulla paura. La Repubblica, https:// ricerca.repubblica.it/repubblica/archivio/repubblica/2020/03/01/coronavirus-chi-soffia-sullapauraNapoli21.html?ref=search

Matino, G. (2020c, 15 de marzo). Compassione al tempo del virus. La Repubblica. https:// ricerca.repubblica.it/repubblica/archivio/repubblica/2020/03/15/compassione-al-tempo-delvirusNapoli14.html?ref=search

Michel, M. (2020, 15 de marzo). 8-M: nadie entona el 'mea culpa'. Las mujeres merecemos una disculpa. El Mundo. https://www.elmundo.es/yodona/ lifestyle/2020/03/15/5e6e81e1fc6c8311408b457d.html

Moernaut, R., Mast, J. y Pauwels, L. (2018). Framing Climate Change: A Multi-level Model. En F. Walter Leal, M. Evangelos, A. Marisa Azul, U. Azeiteiro y H. McGhie (Eds.), Handbook of Climate Change Communication: Vol. 1, (pp. 215-271). Springer.

Montaña Blasco, M., Ollé Castellà, C. y Lavilla Raso, M. (2020). Impacto de la pandemia de Covid-19 en el consumo de medios en España. Revista Latina de Comunicación Social, (78), 155167. https://www.doi.org/10.4185/RLCS-2020-1472 
Moyano, R. (2020, 29 de febrero). El otro pasajero. El Mundo. https://www.elmundo.es/ opinion/2020/02/29/5e 59682b21efa0712d8b45fa.html

Müller-Jung, J. (2020, 5 de febrero). Virale Meute. Frankfurter Allgemeine Zeitung. https:// www.faz.net/aktuell/gesellschaft/gesundheit/coronavirus/coronavirus-fake-news-in-zeiten-einerdrohenden-pandemie-16615854.html

Müller, R. (2020, 3 de marzo). Nicht im Verhältnis. Frankfurter Allgemeine Zeitung. https:// www.faz.net/aktuell/gesellschaft/gesundheit/coronavirus/kampf-gegen-das-coronavirus-nicht-imverhaeltnis-16660351.html

Nevo, E. (2020, 13 de marzo). Se potessi vi inviterei tutti a casa mia. Corriere della Sera. https:// www.corriere.it/opinioni/20 marzo 13/se-potessi-vi-invitereitutti-casa-mia-2032d3d2-654c-11ea86da-7c7313c791fe.shtml

Niola, M. (2020a, 2 de febrero). Se vince la paura del contatto. La Repubblica. https://ricerca. repubblica.it/repubblica/archivio/repubblica/2020/02/02/se-vince-la-paura-del-contatto34. $\underline{\text { html? } \mathrm{ref}=\text { search }}$

Niola, M. (2020b, 24 de febrero). Epidemia e contaminazione. La Repubblica. https://ricerca. repubblica.it/repubblica/archivio/repubblica/2020/02/24/epidemia-e-contaminazione32. $\underline{\text { html? } \mathrm{ref}=\text { search }}$

Núñez-Gómez, P., Abuín-Vences, N., Sierra-Sánchez, J. y Mañas-Viniegra, L. (2020). El enfoque de la prensa española durante la crisis del Covid-19. Un análisis del framing a través de las portadas de los principales diarios de tirada nacional. Revista Latina de Comunicación Social (78), 41-63. https://www.doi.org/10.4185/RLCS-2020-1468

Organización Mundial de la Salud (2020a, 5 de enero). Neumonía de causa desconocida - China. https://www.who.int/csr/don/05-january-2020-pneumonia-of-unkown-cause-china/es/

Organización Mundial de la Salud (2020b, 31 de enero). 2019-nCoV outbreak is an emergency of international concern. https://www.euro.who.int/en/health-topics/health-emergencies/ international-health-regulations/news/news/2020/2/2019-ncov-outbreak-is-an-emergency-ofinternational-concern\#: : text $=2019 \% 2 \mathrm{DnCoV} \% 20$ outbreak $\% 20$ is $\% 20 \mathrm{an} \% 20 \mathrm{emergency} \% 20$ of $\% 20$ international $\% 20$ concern,-AddThis $\% 20$ Sharing $\% 20$ Buttons\&text $=$ The $\% 20$ WHO $\% 20$ Director\%2DGeneral\%2C\%20Dr,PHEIC)\%20on\%2030\%20January\%202020.

Organización Mundial de la Salud (2020c, 11 de marzo). Alocución de apertura del Director General de la OMS en la rueda de prensa sobre la Covid-19 celebrada el 11 de marzo de 2020. https://www.who.int/es/dg/speeches/detail/who-director-general-s-opening-remarks-at-the-mediabriefing-on-covid-19---11-march-2020

Palmero, F. (2020, 2 de febrero). China vista desde Tianjin. El Mundo. https://www.elmundo.es/ opinion/2020/02/02/5e35bff121efa0d0578b460b.html

Pardo, P. (2020, 28 de febrero). COVID-19: ¿una epidemia de 700.000 millones? El Mundo. https://www.elmundo.es/economia/2020/02/28/5e59612a21efa0323a8b4656.html

Park, R. E. (1922). The immigrant press and its control. Harper \& Brothers.

Penati, A. (2020, 11 de marzo). Europa, se ci sei batti un colpo. La Repubblica. https://ricerca. repubblica.it/repubblica/archivio/repubblica/2020/03/11/europa-se-ci-sei-batti-un-colpo34. $\underline{\text { html? } \mathrm{ref}=\text { search }}$ 
Pennekamp, J. (2020, 25 de febrero). Keine Panik. Frankfurter Allgemeine Zeitung. https://www. faz.net/aktuell/wirtschaft/angst-vor-dem-coronavirus-panikmache-in-der-wirtschaft-16649818.html

Pinilla, A. (2008). La transición de papel. Biblioteca Nueva.

Polito, A. (2020, 31 de enero). Fiducia e solidarietà per combattere la paura. Corriere della Sera. https://www.corriere.it/opinioni/20_gennaio_31/fiducia-solidarieta-combattere-paura-8737f328$\underline{445 e-11 \text { ea-b4ca-26f0f6d5d911.shtml }}$

Postiglione, V. (2020, 2 de marzo). Il sentiero stretto per contrastare il virus. Corriere della Sera. https://www.corriere.it/opinioni/20_marzo_02/sentiero-stretto-contrastare-virus-382c0868-5cbf11ea-9c1d-20936483b2e0.shtml?refresh_ce

Ramoneda, J. (2020, 12 de marzo). Salud y política. El País. https:/elpais.com/elpais/2020/03/11/ opinion/1583929575 712098.html

Rampini, F. (2020a, 1 de febrero). Cina, la voce del padrone. La Repubblica, https://ricerca.repubblica. it/repubblica/archivio/repubblica/2020/02/01/cina-la-voce-del-padrone34.html?ref=search

Rampini, F. (2020b, 25 de febrero). Se la Cina diventa un'isola. La Repubblica. https:// ricerca.repubblica.it/repubblica/archivio/repubblica/2020/02/25/se-la-cina-diventa-unisola30. $\underline{\mathrm{html} \text { ?ref }=\text { search }}$

Recalcati, M. (2020a, 5 de febrero). La mente chiusa per virus. La Repubblica. https:// ricerca.repubblica.it/repubblica/archivio/repubblica/2020/02/05/la-mente-chiusa-per-virus 26. $\underline{\mathrm{html} \text { ?ref }=\text { search }}$

Recalcati, M. (2020b, 23 de febrero). Resistere al panico. La Repubblica. https://ricerca. repubblica.it/repubblica/archivio/repubblica/2020/02/23/resistere-al-panico34.html?ref=search

Recalcati, M. (2020c, 14 de marzo). La nuova fratellanza. La Repubblica. https://ricerca. repubblica.it/repubblica/archivio/repubblica/2020/03/14/la-nuova-fratellanza34.html?ref=search

Redondo, J. (2020, 9 de febrero). Socialismo 'perfecto'. El Mundo. https://www.elmundo.es/ opinion/columnistas/2020/02/09/5e3ebf1421efa032088b4618.html

Romagnoli, G. (2020, 22 de febrero). Il virus del contrappasso. La Repubblica. https:// ricerca.repubblica.it/repubblica/archivio/repubblica/2020/02/22/il-virus-del-contrappasso38. $\underline{\mathrm{html} \text { ?ref }=\text { search }}$

Román-San-Miguel, A., Sánchez-Gey Valenzuela, N. y Elías-Zambrano, R. (2020). Las fake news durante el Estado de Alarma por COVID-19. Análisis desde el punto de vista político en la prensa española. Revista Latina de Comunicación Social, (78), 359-391. https://www.doi.org/10.4185/ $\underline{\text { RLCS-2020-1481 }}$

Sádaba, T. (2001). Origen, aplicación y límites de la 'teoría del encuadre' (framing) en comunicación, Comunicación y Sociedad, 2, 143-175.

Santangelo, M. (2020, 28 de febrero). Confusione da Coronavirus. La Repubblica. https://ricerca. repubblica.it/repubblica/archivio/repubblica/2020/02/28/confusione-da-coronavirusNapoli21. html?ref=search

Scalfari, E. (2020, 8 de marzo). Quei valori che il virus mette in gioco. La Repubblica, https:// ricerca.repubblica.it/repubblica/archivio/repubblica/2020/03/08/quei-valori-che-il-virus-mette-ingioco34.html?ref=search 
Scheufele, D. A. (1999). Framing as a Theory of Media Effects, Journal of Communication, 49(1) 103-122.

Schmidt, L. (2020, 4 de febrero). Ein Feind, der sich nicht in die Karten gucken lässt. Frankfurter Allgemeine Zeitung. https://www.faz.net/aktuell/gesellschaft/gesundheit/coronavirus/coronavirusungewissheit-rechtfertigt-keine-panikmache-16615713.html

Scholemann, J. (2020, 25 de febrero). Wenn die Gefahr näher rückt. Süddeutsche Zeitung.. https:// www.sueddeutsche.de/kultur/coronavirus-wenn-die-gefahr-naeher-rueckt-1.4818688

Semetko, H. A., y Valkenburg, P. M. (2000). Framing European politics: a content analysis of press and television news. Journal of Communication, 50(2), 93-109. https://doi. org/10.1111/j.1460-2466.2000.tb02843.x

Sturm, P. (2020, 24 de febrero). Keine Panik - aber nicht abwiegeln. Frankfurter Allgemeine Zeitung. https://www.faz.net/aktuell/politik/kommentar-das-coronavirus-ist-anders-undunheimlich-16649523.html

Thelwall, M. y Levitt, J. M. (2020). Retweeting Covid-19 disability issues: Risks, support and outrage. El profesional de la información, 29(2). https://doi.org/10.3145/epi.2020.mar.16

Thelwall, M. y Thelwall, S. (2020). Covid-19 tweeting in English: Gender differences. El profesional de la información, 29(3). https://doi.org/10.3145/epi.2020.may.01

Torreblanca, J.I. (2020, 15 de febrero). China Chernóbil. El Mundo. https://www.elmundo.es/ opinion/columnistas/2020/02/15/5e46adb2fdddff33668b4597.html

Torres-Salinas, D. (2020). Ritmo de crecimiento diario de la producción científica sobre Covid-19. Análisis en bases de datos y repositorios en acceso abierto. El profesional de la información, 29(2). https://doi.org/10.3145/epi.2020.mar.15

Touri, M. y Koteyko, N. (2014). Using corpus linguistic software in the extraction of news frames: towards a dynamic process of frame analysis in journalistic texts. International Journal of Social Research Methodology, 18(6), 601-616. http://dx.doi.org/10.1080/13645579 .2014 .929878

Trueba, D. (2020, 17 de febrero). El pangolín. El País. https://elpais.com/elpais/2020/02/17/ opinion/1581944743 034214.html

Tsai Tseng, C. (2020, 29 de enero). El menú del Año Nuevo lunar. El País. https://elpais.com/ ccaa/2020/01/29/madrid/1580307870_823900.html

Ulrich, S. (2020, 24 de febrero) Von der Macht der emergenza. Süddeutsche Zeitung. https://www. sueddeutsche.de/politik/coronavirus-italien-notlagen-emergenza-kommentar-1.4813473

Veser, R. (2020, 7 de febrero). Politisches Virus. Frankfurter Allgemeine Zeitung. https:// www.faz.net/aktuell/politik/ausland/was-bedeutet-der-tod-von-li-wenliang-fuer-chinaspolitik-16622995.html

Vicent, M. (2020, 15 de marzo). Dar la talla. El País. https://elpais.com/elpais/2020/03/13/ opinion/1584119262_000771.html

Villa Gracia, D. y Cerdán Martínez, V. (2020). Bulos durante la pandemia del Covid-19 en España: un estudio a través de Google Trends. Revista Latina de Comunicación Social, (78), 169182. https://www.doi.org/10.4185/RLCS-2020-1473 
Von Altenbockum, J. (2020, 27 de febrero). Der Bund ist arrogant. Frankfurter Allgemeine Zeitung. https://www.faz.net/aktuell/gesellschaft/gesundheit/coronavirus/kommentar-zu-coronazustaendigkeiten-die-bund-ist-arrogant-16654793.html

Xifra, J. (2020). Comunicación corporativa, relaciones públicas y gestión del riesgo reputacional en tiempos del Covid-19. El profesional de la información, 29(2) https://doi.org/10.3145/epi.2020. $\underline{\operatorname{mar} .20}$

Zinkant, K. (2020, 28 de enero). Geduld statt Panik. Süddeutsche Zeitung. https://www. sueddeutsche.de/politik/coronavirus-kommentar-1.4774671 